\title{
Genome analyses provide insights into the evolution and adaptation of the eukaryotic Picophytoplankton Mychonastes homosphaera
}

\author{
Changqing Liu ${ }^{1,2+}$, Xiaoli Shi ${ }^{i^{*}+}$, Fan Wu ${ }^{1,2}$, Mingdong Ren ${ }^{1,2}$, Guang Gao ${ }^{1}$ and Qinglong Wu $u^{1,2}$
}

\begin{abstract}
Background: Picophytoplankton are abundant and can contribute greatly to primary production in eutrophic lakes. Mychonastes species are among the common eukaryotic picophytoplankton in eutrophic lakes. We used thirdgeneration sequencing technology to sequence the whole genome of Mychonastes homosphaera isolated from Lake Chaohu, a eutrophic freshwater lake in China.

Result: The 24.23 Mbp nuclear genome of M.homosphaera, harboring 6649 protein-coding genes, is more compact than the genomes of the closely related Sphaeropleales species. This genome streamlining may be caused by a reduction in gene family number, intergenic size and introns. The genome sequence of M.homosphaera reveals the strategies adopted by this organism for environmental adaptation in the eutrophic lake. Analysis of cultures and the protein complement highlight the metabolic flexibility of M.homosphaera, the genome of which encodes genes involved in light harvesting, carbohydrate metabolism, and nitrogen and microelement metabolism, many of which form functional gene clusters. Reconstruction of the bioenergetic metabolic pathways of M.homosphaera, such as the lipid, starch and isoprenoid pathways, reveals characteristics that make this species suitable for biofuel production.
\end{abstract}

Conclusion: The analysis of the whole genome of $M$. homosphaera provides insights into the genome streamlining, the high lipid yield, the environmental adaptation and phytoplankton evolution.

Keywords: Picophytoplankton, Mychonastes, Genome, Adaptation

\section{Background}

As the most urbanized and developed region of China, lake eutrophication is common in the middle-lower reaches of the Yangtze River. Picophytoplankton (with cell diameters $<3 \mu \mathrm{m}$ ) are abundant and can contribute $9-55 \%$ of primary productivity in eutrophic lakes $[1,2]$.

\footnotetext{
* Correspondence: xlshi@niglas.ac.cn

${ }^{+}$Changqing Liu and Xiaoli Shi contributed equally to this work.

'State Key Laboratory of Lake Science and Environment, Nanjing Institute of Geography and Limnology, Chinese Academy of Sciences, Nanjing 210008, China

Full list of author information is available at the end of the article
}

Mychonastes species are the dominant eukaryotic picophytoplankton in most eutrophic lakes (e.g., Lake Chaohu and Lake Poyang in China) [2, 3]. However, the mechanism underlying the dominance of Mychonastes in eutrophic lakes is not clear. Using a whole-genome approach, we specifically focused on the gene sets and metabolic pathways of Mychonastes that may facilitate its dominance under the environmental conditions of most eutrophic lakes $[4,5]$. Although given the decreasing cost of sequencing [6-8], many phytoplankton have been sequenced [9-12], the genome sequencing of

(c) The Author(s). 2020 Open Access This article is licensed under a Creative Commons Attribution 4.0 International License, which permits use, sharing, adaptation, distribution and reproduction in any medium or format, as long as you give appropriate credit to the original author(s) and the source, provide a link to the Creative Commons licence, and indicate if changes were made. The images or other third party material in this article are included in the article's Creative Commons licence, unless indicated otherwise in a credit line to the material. If material is not included in the article's Creative Commons licence and your intended use is not permitted by statutory regulation or exceeds the permitted use, you will need to obtain permission directly from the copyright holder. To view a copy of this licence, visit http://creativecommons.org/licenses/by/4.0/. The Creative Commons Public Domain Dedication waiver (http://creativecommons.org/publicdomain/zero/1.0/) applies to the data made available in this article, unless otherwise stated in a credit line to the data. 
picophytoplankton has only targeted marine species thus far $[13,14]$. The absence of genome information for picophytoplankton in freshwater lakes prevents us from recognizing the picophytoplankton niche and its ecological role in the lake.

Mychonastes belong to the order Sphaeropleales within the class Chlorophyceae. Sphaeropleales is a large group that contains some of the most common freshwater algae [15]. The genome sequences of Sphaeropleales are a hot research topic because some of these species show enormous potential for biofuel production [10, 11, 16], with robust growth and a high lipid content. Thus far, six genomes of Sphaeropleales, belonging to Scenedesmus quadricauda [9], Raphidocelis subcapitata [10], Monoraphidium neglectum [11], Tetradesmus obliquus [12], Chromochloris zofingiensis [17], and Coelastrella sp. [18], have been sequenced. These Sphaeropleales genomes provide much information for Mychonastes genome research and contribute to explaining the evolution and adaptation of Mychonastes. Comparative analyses of genomes would provide insights into the environmental adaptation and genome evolution of Sphaeropleales.

In order to further increase knowledge about the evolution and adaptation of freshwater picophytoplankton, we isolated a Mychonastes strain from Lake Chaohu, a highly eutrophic lake, and sequenced its complete genome by using third-generation sequencing (PacBio Sequel). Here, we conducted combined analysis of the complete genome sequences of M.homosphaera and other Sphaeropleales species as well as picophytoplankton species to investigate the evolutionary history and environmental adaptation of M.homosphaera.

\section{Results}

\section{Phylogenetic analyses}

We performed phylogenetic analyses using $18 \mathrm{~S}$ rRNA to verify the phylogenetic position of M.homosphaera within Viridiplantae, with red algae as an outgroup (Fig. 1). In the tree, M.homosphaera was clustered by family, forming a monophyletic group with the other Mychonastaceae species. There was robust support (BP = 95) for the inclusion of M.homosphaera in Mychonastaceae, where it was positioned closest to Mychonastes homosphaera (AB025423) isolated from Lake Kinneret, Israel [19].

\section{General features of the nuclear genome}

We sequenced $5.8 \mathrm{Gbp}$ reads using the PacBio Sequel system. Based on assembly and correction, we obtained M.homosphaera genome statistics (genome size: 24.23 $\mathrm{Mb}$, contig N50: $2 \mathrm{Mb}$, contig number: 31) (Table 1). The assembly was analyzed regarding its completeness based on sequence homology to the OrthoDB eukaryote dataset (www.orthodb.org), showing 89.4\% complete BUSCOs (Benchmarking Universal Single-Copy Orthologs) (Supplementary Table 1), which was higher than the percentages for the sequenced Sphaeropleales species (C.zofingiensis 84.5\%, M.neglectum 58.5\%, and T.obliquus 79.9\%) except for R.subcapitata (91.7\%) [10]. Therefore, we obtained a nearly complete genome for M.homosphaera.

A total of 53,016 SSRs (simple sequence repeats) were masked by MISA (MIcroSAtellite identification tool), which accounted for $20.13 \%$ of the M.homosphaera genome. There were six types of SSR in the M.homosphaera

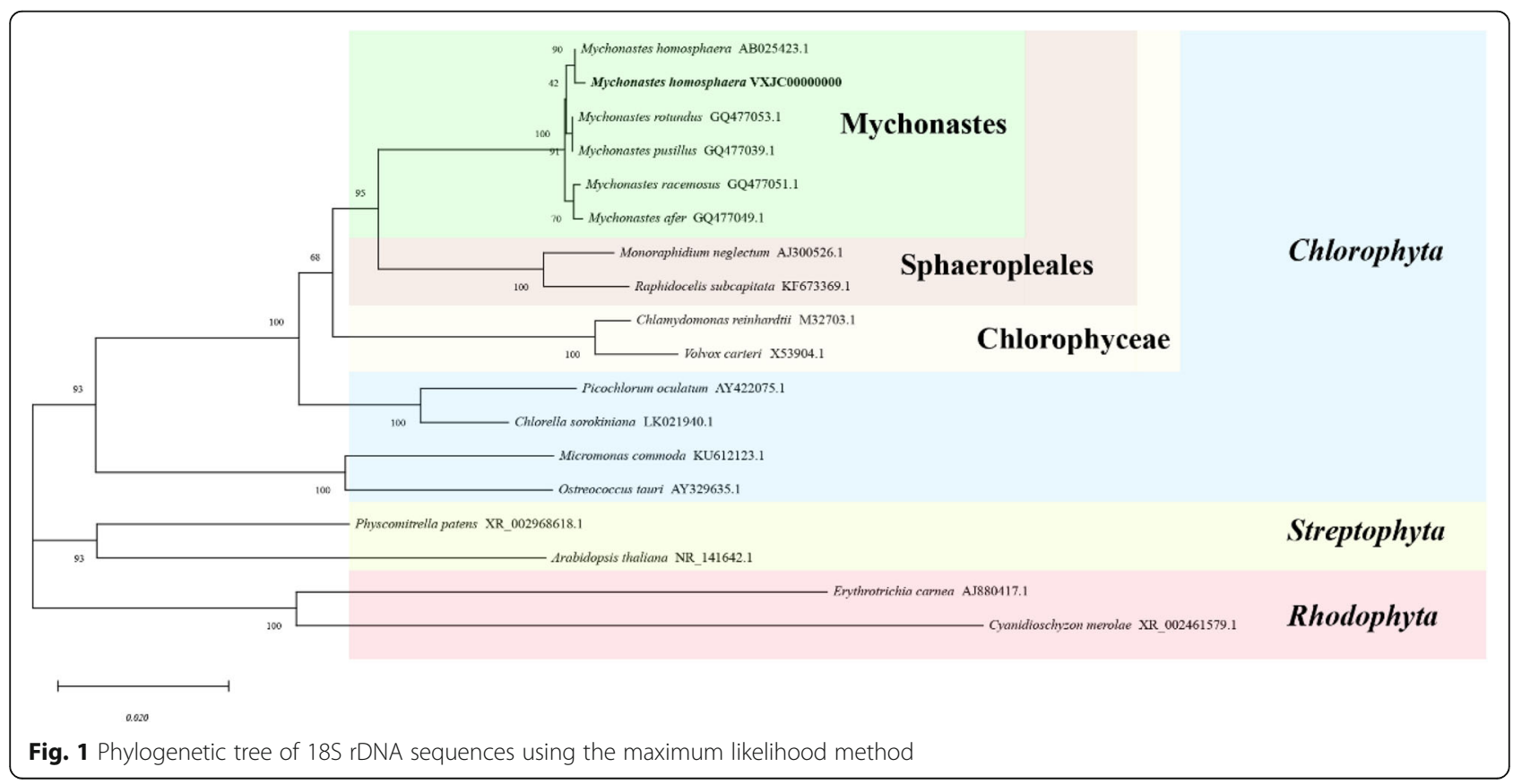


Table 1 Mychonastes homosphaera genome statistics

\begin{tabular}{ll}
\hline Assembly statistics for the nuclear genome & \\
Assembly genome size (Mbp) & 24.23 \\
Genomic G + C content (\%) & 72.4 \\
Contig number & 31 \\
Number of Contig N50 & 5 \\
Length of Contig N50 (kbp) & 2001 \\
miRNA number & 0 \\
rRNA number & 26 \\
snRNA number & 11 \\
tRNA number & 64 \\
Gene statistics & \\
Predicted number of nuclear genes & 6649 \\
Number of annotated genes & $5711(85.89 \%)$ \\
Average transcript length (bp) & 2952.98 \\
Average CDS length (bp) & 1569.72 \\
Exon number & 32,277 \\
Average exon number per gene & 4.85 \\
Average exon length (bp) & 323.36 \\
Intron number & 25,628 \\
Average intron number per gene & 3.85 \\
Average intron length (bp) & 358.88 \\
Coding (\%) & $43.1 \%$ \\
\hline
\end{tabular}

genome (Supplementary Table 2), and the vast majority of SSR $(52,206$ repeat sequences) belong to those three types, p1, p2 and p3. Noncoding RNA in the genome was annotated differently; 26 rRNAs (including $618 \mathrm{~S}$ rRNAs, 7 28S rRNAs, 6 5.8S rRNAs, and 7 5S rRNAs), 46 tRNAs and 11 snRNA were annotated. A total of 6649 protein-coding genes were predicted in the genome, with an average transcript length of $2952.98 \mathrm{bp}$ and an average CDS (coding sequence) length of $1569.72 \mathrm{bp}$.
Out of these, 5711 protein-coding genes $(85.89 \%$ of the predicted genes) were annotated, and coding sequences constituted $43.1 \%$ of the genome, with a mean exon length and mean intron length of 323.36 and $358.88 \mathrm{bp}$, respectively. The protein-coding genes contained 25,628 introns, with a density of 3.85 introns per gene, and 32 , 277 exons, with a density of 4.85 introns per gene.

The nuclear genome of M.homosphaera was the smallest among those known for Sphaeropleales, at less than half of the size of the known whole genome sequences from Sphaeropleales. Unlike other Sphaeropleales species, M.homosphaera exhibited small intergenic regions and a high coding rate, which is common in other picophytoplankton (Fig. 2); therefore, the coding percentage of M.homosphaera (43.1\%) was higher than that of other Sphaeropleales (expect R.subcapitata). Furthermore, M.homosphaera exhibited the highest GC content (72.4\%) among the Sphaeropleales species examined to date.

\section{General features of chloroplast and mitochondrial genomes}

M.homosphaera is the Sphaeropleales picophytoplankton, we compared its organelle genomes with those of other Sphaeropleales species (M.neglectum and R.subcapitata) and those of two marine picophytoplanktons (Ostreococcus tauri and Micromonas commoda), to understand the genome features of M.homosphaera. The complete chloroplast genome of M.homosphaera was one of the smallest among Sphaeropleales species identified thus far $(102,771 \mathrm{bp}$ in size, approximately twothirds the size in other Sphaeropleales species), and it was AT-rich $(60.03 \%)$ and circular with no inverted repeats or introns (Figs. 2 and 3). Surprisingly, M.homosphaera exhibited the maximum number of chloroplast genes among known Sphaeropleales, including 72 conserved protein-coding genes, 6 rRNAs and 35 tRNAs.

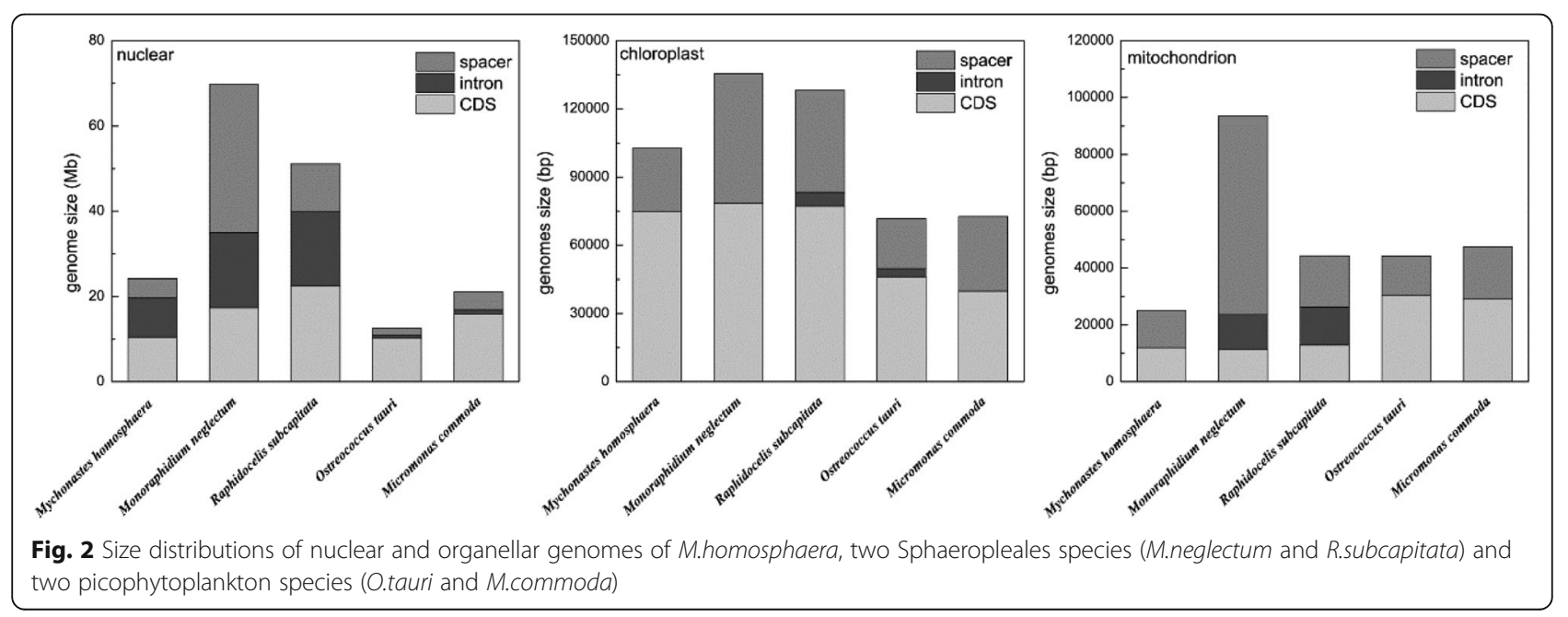




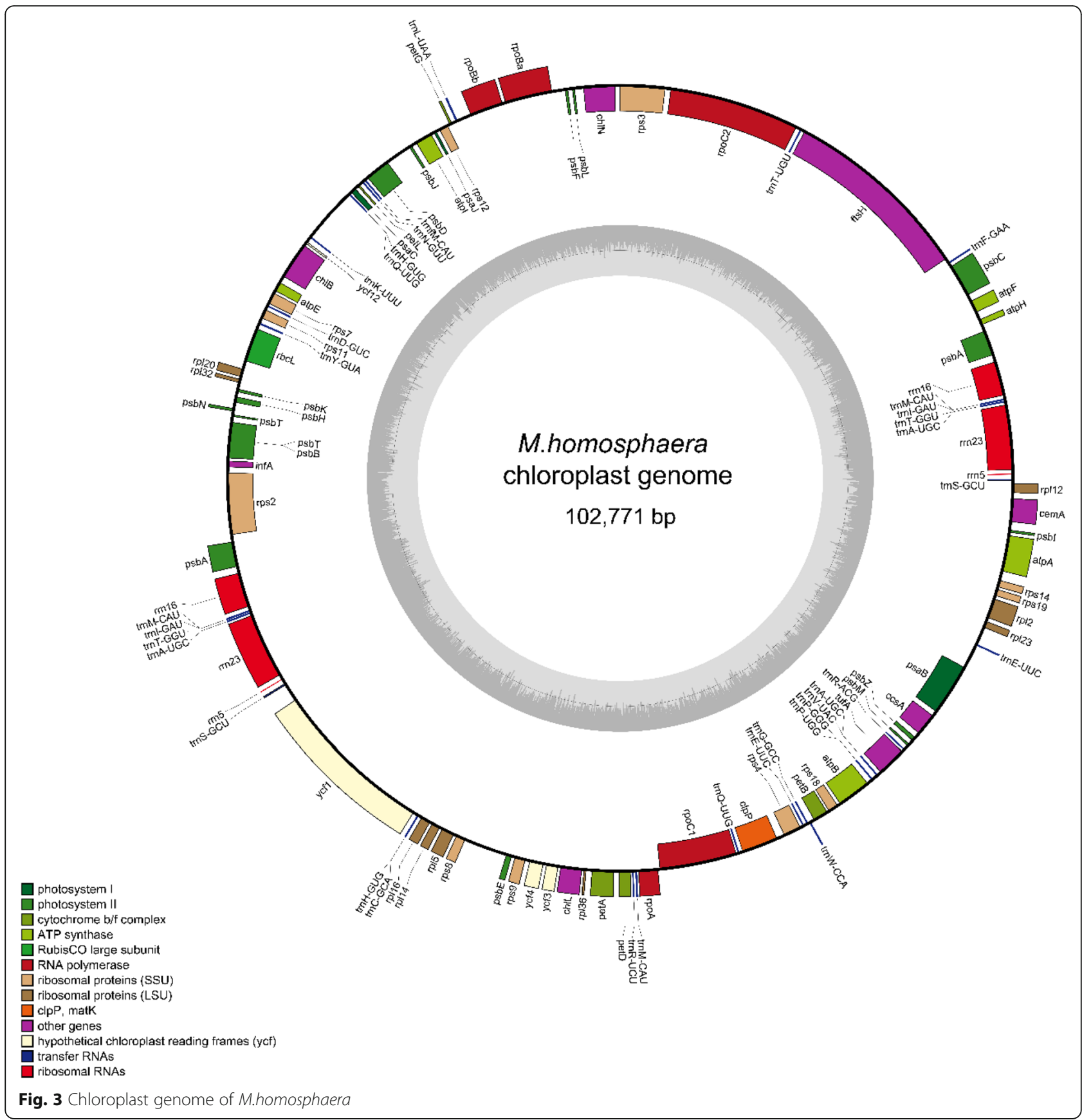

Intronic ORFs (open reading frames) were not found in the chloroplast genome. Compared with other Sphaeropleales species, M.homosphaera presented extra rpl32 and apoprotein A1 genes (Supplementary Table 3). However, in fact, the CDS length of M.homosphaera was similar to those of other Sphaeropleales species.

Extreme gene compaction was also founded in the mitochondrion (25,091 bp, 20.7\% GC) (Figs. 2 and 4), which presented the smallest mitochondrial genome with the highest protein coding density identified to date within Sphaeropleales species while retaining the same genes found in other species (Supplementary Table 4). There were 13 conserved protein-coding genes, 6 fragmented rRNAs, and 22 tRNAs. The protein-coding genes included subunits of NADH dehydrogenase (nad1, nad2, nad3, nad4, nad4L, nad5 and nad6), ubichinol cytochrome c reductase (cob), cytochrome oxidases (cox1, cox2a and cox3) and 2 ATP synthases (atp6 and atp9). Similar with other Sphaeropleales species, the $16 \mathrm{~S}$ rRNA and 23S rRNA sequences were separated into two and four fragments, respectively. Only a threonine-tRNA gene was missing in the mitochondrial genome, and 


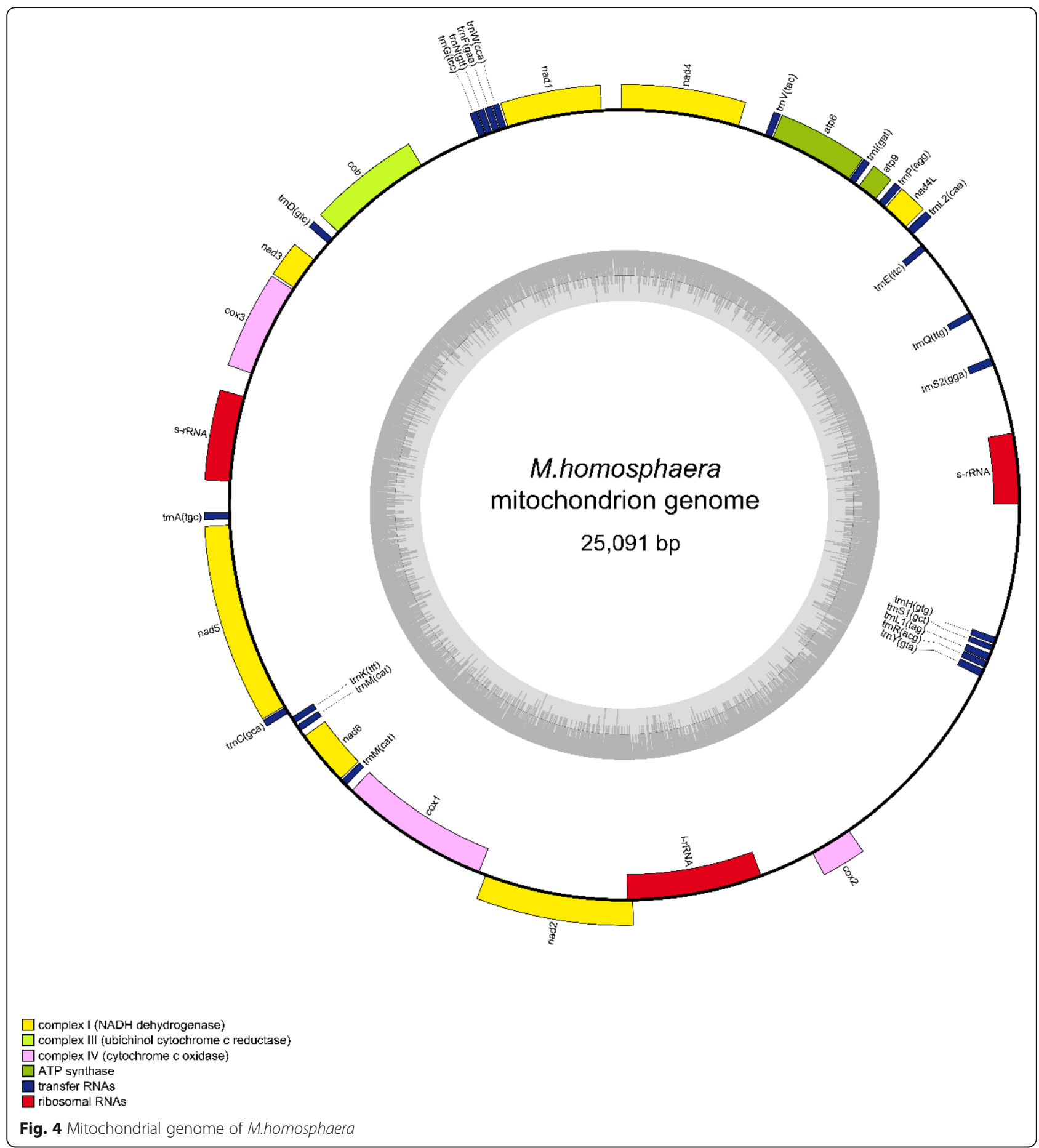

there was an almost complete set of tRNAs for translation. In addition, we found that Cox 2 was split; its Nterminus (Cox2a) was encoded by the mitochondrial genome, and the C-terminus of Cox2 (Cox2b) was encoded by the nuclear genome. Unlike other Sphaeropleales species, there were no introns in the M.homosphaera mitochondrial genome. However, the lack of introns had also been found in the mitochondrial genome of picophytoplankton such as Ostreococcus tauri and Micromonas commoda [13, 14] (Fig. 2).

\section{Gene families of the M.homosphaera genus}

To infer gene families variation in M.homosphaera in evolution, we compared its homologous genes with those of model organism, such as the red algae Cyanidioschyzon merolae, the green plant Arabidopsis 
thaliana, and two green algae (O.tauri and Chlamydomonas reinhardtii). The number of common gene families was 1814, accounting for approximately half of the M.homosphaera gene families (Fig. 5). Almost all of M.homosphaera gene families could be found in plants and algae, implying the evolutionarily ancient divergence of Plantae (red algae, green algae, and plants) [20]. In accord with the evolutionary direction, 529 gene families were shared by M.homosphaera and the green alga C.reinhardtii, whereas 24 and 5 gene families were only shared by M.homosphaera with Arabidopsis thaliana and C.merolae, respectively.

A similar comparison in green algae including Sphaeropleales species (such as M.neglectum, R.subcapitata and M.homosphaera) and C.reinhardtii was also performed (Fig. 6). The common numbers of gene families for green algae (M.neglectum, R.subcapitata, M.homosphaera and C.reinhardtii) was 4048, and for Sphaeropleales (M.neglectum, R.subcapitata and M.homosphaera) was 4393. M.homosphaera showed a lack of unique gene families, and more than $90 \%$ of its gene families were common gene families. In addition, comparison of M.homosphaera genes to the nonredundant protein database yielded top hits from a variety of organisms, among which the highest frequency was found for the species M.neglectum and the taxon Chlorophyta (Fig. 7), which was expected on the basis of the phylogeny of M.homosphaera.

\section{Genome annotation and insights from the genome}

The functions of 5711 proteins were predicted in the biochemical pathways of M.homosphaera, among which 3948 proteins were annotated based on homology with proteins in public databases. Furthermore, the annotated proteins were divided into functional categories based on the GO (Gene Ontology) database. The predicted proteins in M.homosphaera genome were divided based on three GO domains: molecular function, cellular component and biological process (Fig. 8).

Functional analyses using KEGG (Kyoto Encyclopedia of Genes and Genomes) categories showed that most of the functions were shared among phytoplankton, although M.homosphaera possessed the minimum number of genes among phytoplankton families (Fig. 9). C.reinhardtii, M.neglectum and M.commoda represent the

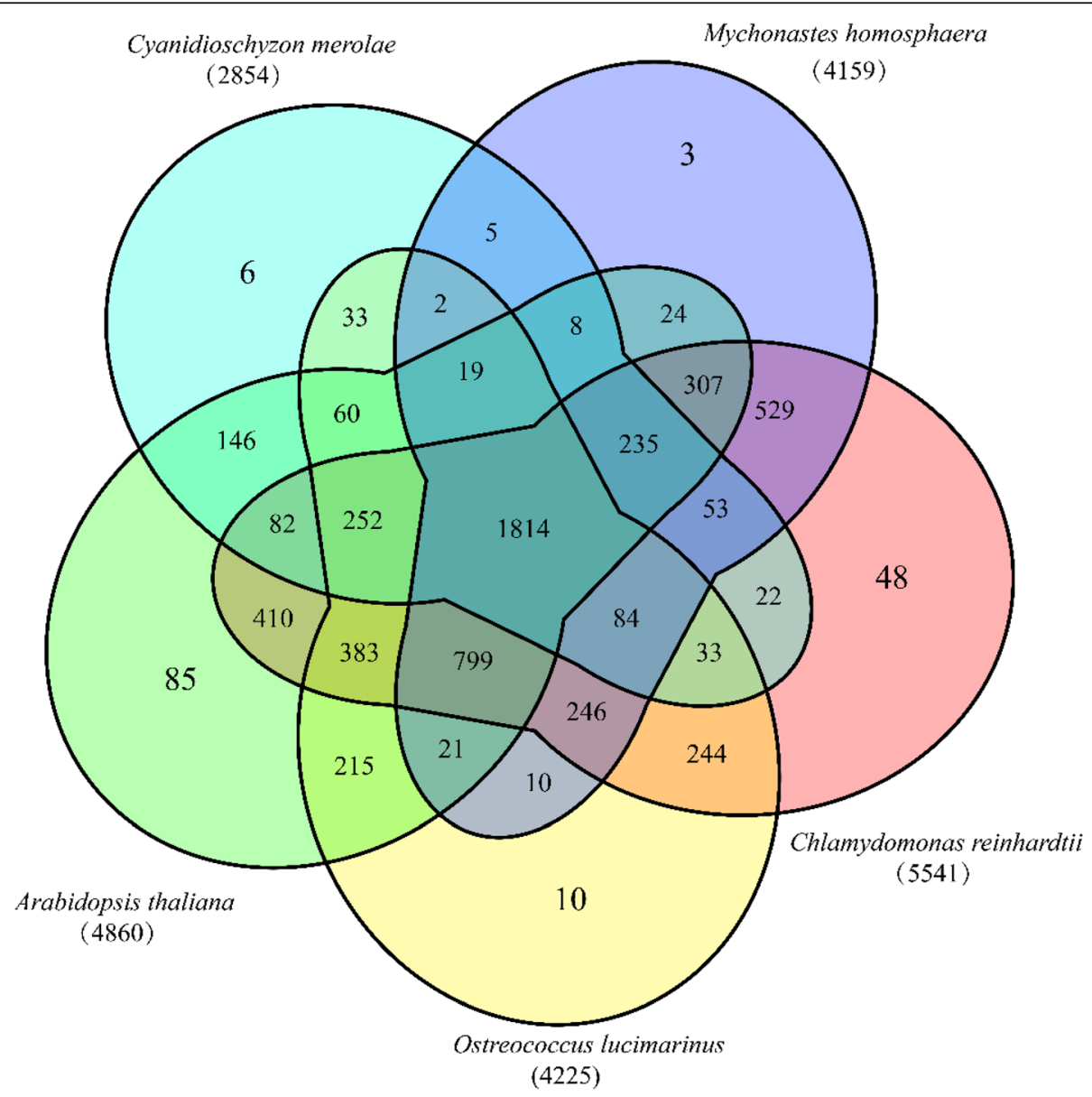

Fig. 5 Venn diagram of the gene families of M.homosphaera and other Viridiplantae 


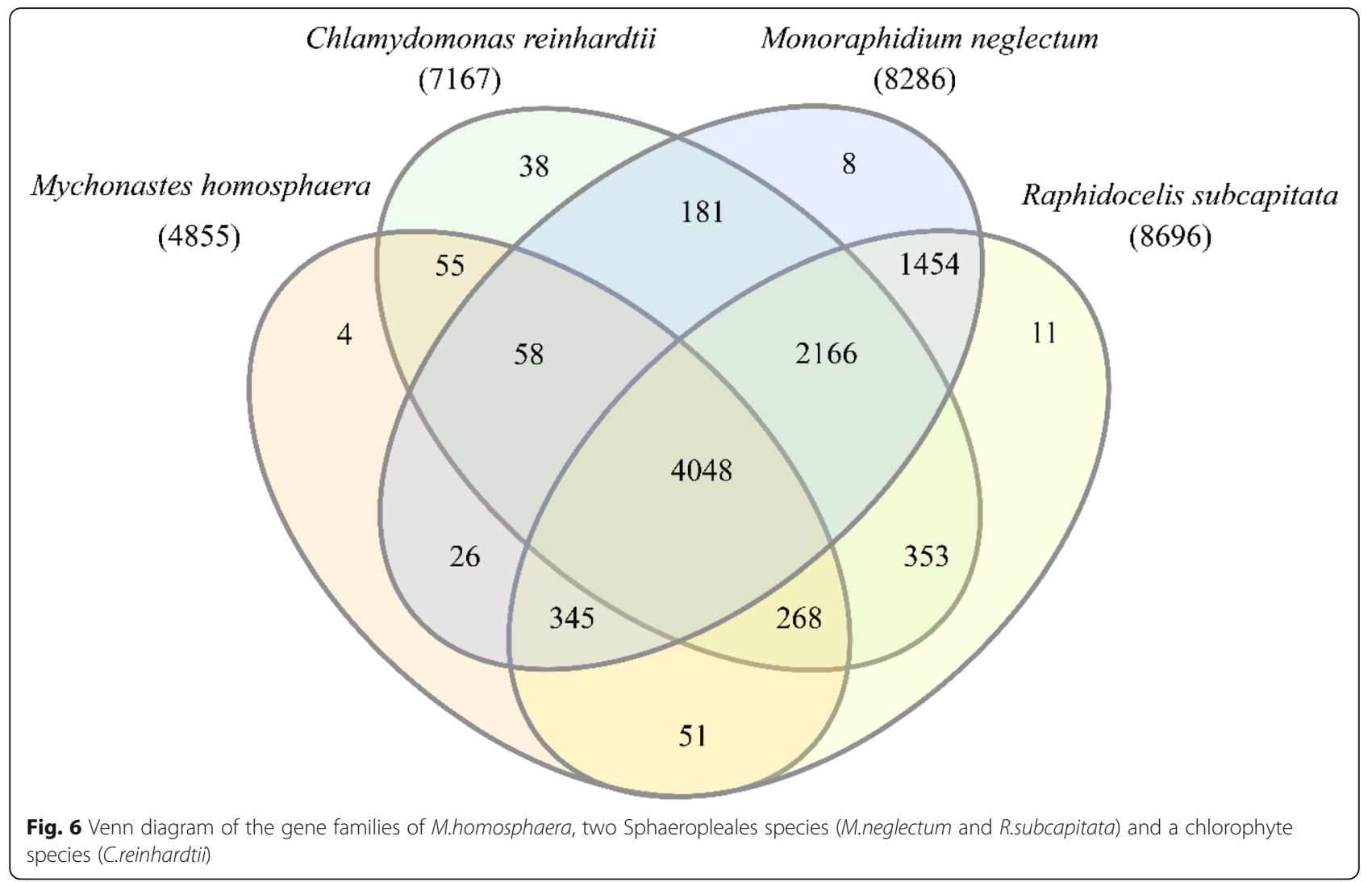

chlorophyte, Sphaeropleales and picophytoplankton, respectively. However, the number of total genes in M.homosphaera were quite similar to those in other algae. Though the proportion of M.homosphaera genes related to various types of metabolism was relatively small, it possessed genes related to xenobiotic biodegradation, which are lacking in other algae. M.homosphaera contained a higher proportion of genes related to environmental information processing than other algae, especially signal transduction genes. Furthermore,

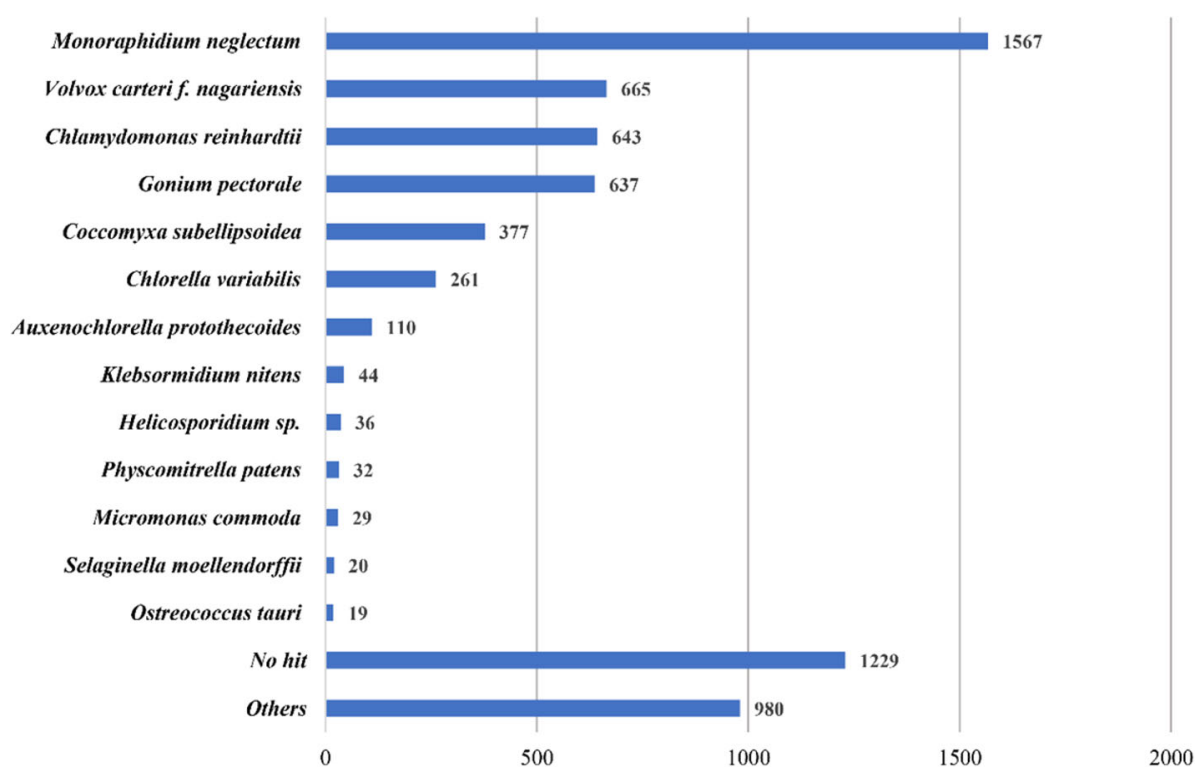

Fig. 7 Top BLASTp hits of M.homosphaera compared with the nonredundant protein database 


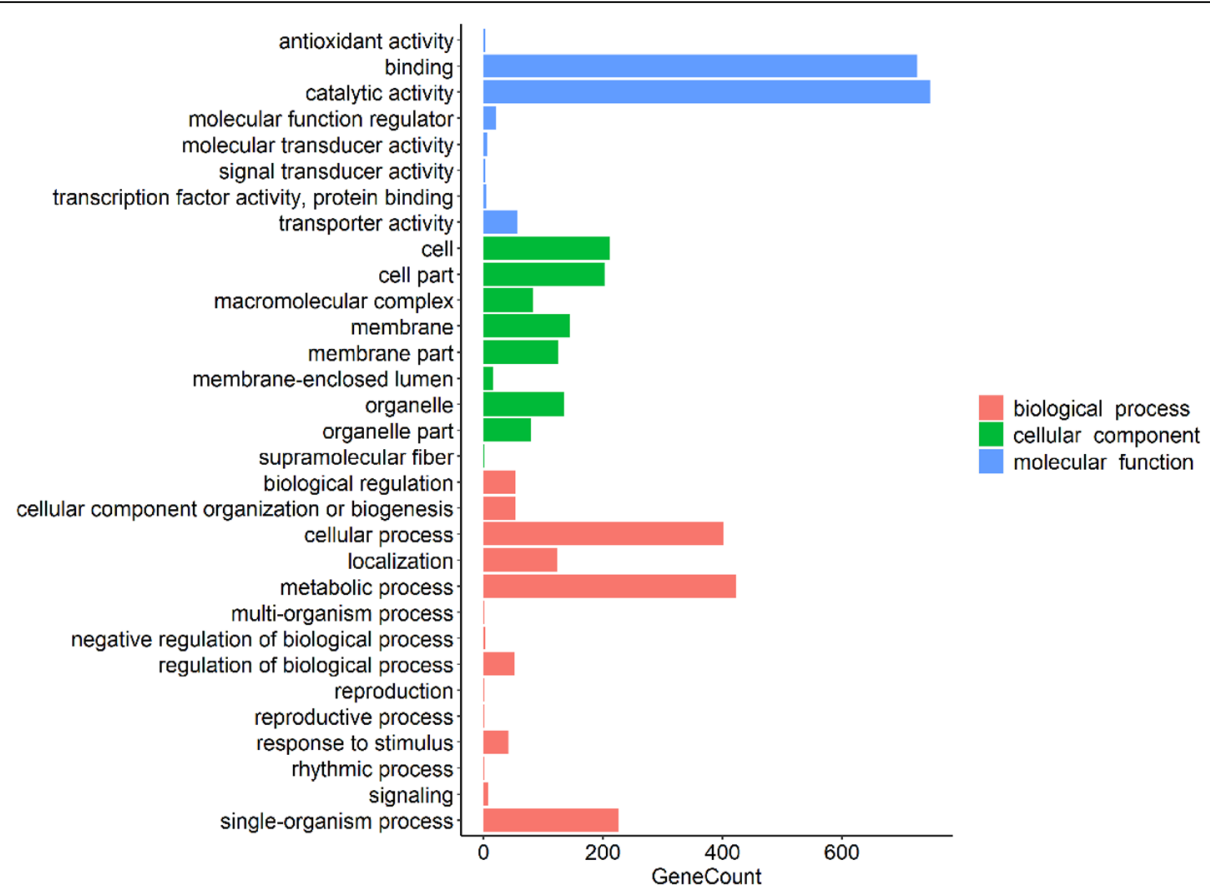

Fig. 8 Gene Ontology (GO) assignments for M.homosphaera The 31 most extensive GO terms of the three GO supercategories "molecular function" (blue), "cellular component" (green) and "biological process" (red) are shown

M.homosphaera possessed all cellular process pathway genes, while M.neglectum possess transport, catabolism, cell growth and death pathway genes, and C.reinhardtii and M.commoda only possess transport and catabolism pathway genes.

The genes of M.homosphaera facilitate its dominance within the environmental conditions of the lake

M.homosphaera are widely distributed in shallow turbid lakes and river-connected eutrophic lakes, experiencing complex and changing environmental conditions such as varying water exchange rates, light conditions, temperatures and nutrition concentrations. Genome analysis provides insights into the mechanism for adaptation to these environmental conditions.

\section{Light Harvesting}

M.homosphaera possessed genes homologous to phototropins and cryptochromes, which generally act as bluelight photoreceptors in certain eukaryotes. A phytochrome gene homolog was also identified; phytochromes function as red/far-red light and temperature sensors. However, there were no rhodopsin green-light photoreceptors in M.homosphaera (Fig. 10).

The xanthophyll cycle is a major mechanism for the dissipation of excess light energy for plant photoprotection [21, 22]. Two key enzymes of the xanthophyll cycle, VDE (violaxanthin de-epoxidase) and ZE (zeaxanthin epoxidase), can be found in M.homosphaera.
In addition, Fe-Mn SOD (superoxide dismutase)-encoding genes were found. Furthermore, the M.homosphaera genome contained the full suite of genes involved in photosynthesis, including 13 genes encoding components of the LHC (light-harvesting complex), which absorbs light and transfers it to photosynthetic reaction centers.

\section{Carbohydrate metabolism}

Carbon concentrations and carbon assimilation have been described in many algae [20, 23, 24], and we were able to identify the genes required for both C3 (Calvin cycle)- and C4-type carbon assimilation (Supplementary Table 5). The key enzymes in these two types of metabolism are carbonic anhydrases, which catalyze the reversible conversion of $\mathrm{CO}_{2}$ to $\mathrm{HCO}_{3}{ }^{-}$. In addition, $\mathrm{HCO}_{3}{ }^{-}$must be transported into the cell by a bicarbonate transporter or be converted into $\mathrm{CO}_{2}$ by carbonic anhydrases. These two enzymes were found in M.homosphaera genome (Fig. 10).

Based on the obtained protein information and the Randor model [24], we describe potential carbonconcentrating mechanisms in M.homosphaera (Fig. 10). There are two potential $\mathrm{C} 4$ carbon-concentrating mechanisms, which involve the production of malate in the cytosol and the mitochondria, and they provide possibilities for carbon concentration under different environmental conditions. 


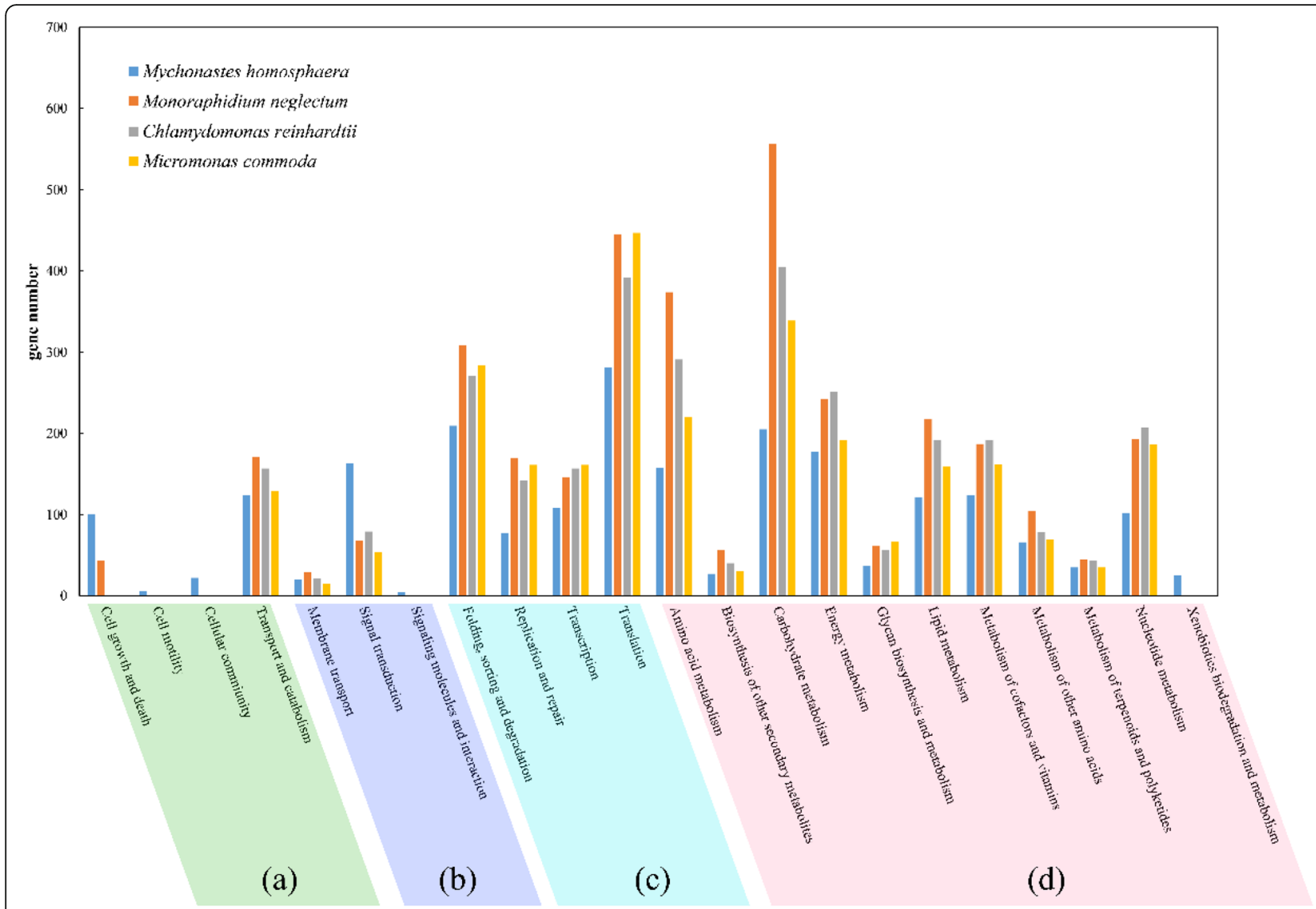

Fig. 9 Functional comparison of M.homosphaera and other phytoplankton according to KEGG classification. (a), (b), (c) and (d) represent cellular processes, environmental information processing, genetic information processing and metabolism, respectively

\section{Nitrogen assimilation}

Nitrogen is the most common nutrient limiting primary production in freshwater, estuarine and coastal ecosystems. M.homosphaera possessed genes encoding nitrate, nitrite, and ammonium transporters, which indicates that M.homosphaera uses multiple forms of nitrogen (Supplementary Table 6). Additionally, the M.homosphaera genome encoded one $\mathrm{NAD}(\mathrm{P}) \mathrm{H}$-nitrate reductase, for the reduction of nitrate to nitrite, and one ferredoxin nitrite reductase, to catalyze the reduction of nitrite. Additionally, the M.homosphaera genome encoded all urea cycle components except for arginase, including carbamoyl-phosphate synthetase I (large and small subunits), ornithine carbamoyltransferase, arginosuccinate synthase, and arginosuccinate lyase.

\section{Microelements}

M.homosphaera lacked all genes for common iron acquisition, although iron is involved in many metabolic activities, such as photosynthesis, respiration and nitrate reduction. Therefore, there may be a novel iron acquisition system in M.homosphaera that is different from those of other phytoplankton. The lack of iron transport components is also found in other picophytoplankton, such as Ostreococcus [25], which also possesses a small genome size and gene number. Plants generally utilize copper transporter (CTR) family proteins to transport $\mathrm{Cu}$ ions into the cytosol [26], and these proteins were not found in M.homosphaera. However, there were two ZIP (Zrt, Irt-like Protein) genes in this organism, which are speculated to function in $\mathrm{Cu}$ acquisition, perhaps showing the capacity to transport $\mathrm{Cu}^{2+}[27]$.

In methionine synthesis, in addition to the $\mathrm{VB}_{12}$ (vitamin B12)-dependent pathway, there are $\mathrm{VB}_{12}$-independent pathways in phytoplankton [28]. However, M.homosphaera exhibited METH (methionine synthase) but not METE $\left(\mathrm{B}_{12^{-}}\right.$ independent methionine synthase), indicating that it only performs methionine synthesis via the $\mathrm{VB}_{12}$-dependent pathway. Therefore, M.homosphaera shows strict dependence on $\mathrm{VB}_{12}$. $\mathrm{VB}_{12}$ can only be produced by bacteria (both eubacteria and archaea) in nature [29]. Therefore, M.homosphaera must acquire $\mathrm{VB}_{12}$ or a precursor from the lake environment or associated bacteria [30]. In addition, the M.homosphaera genome possessed a complete pathway for thiamine biosynthesis (Supplementary Table 7), which increases biotic and stress resistance [31, 32]. 


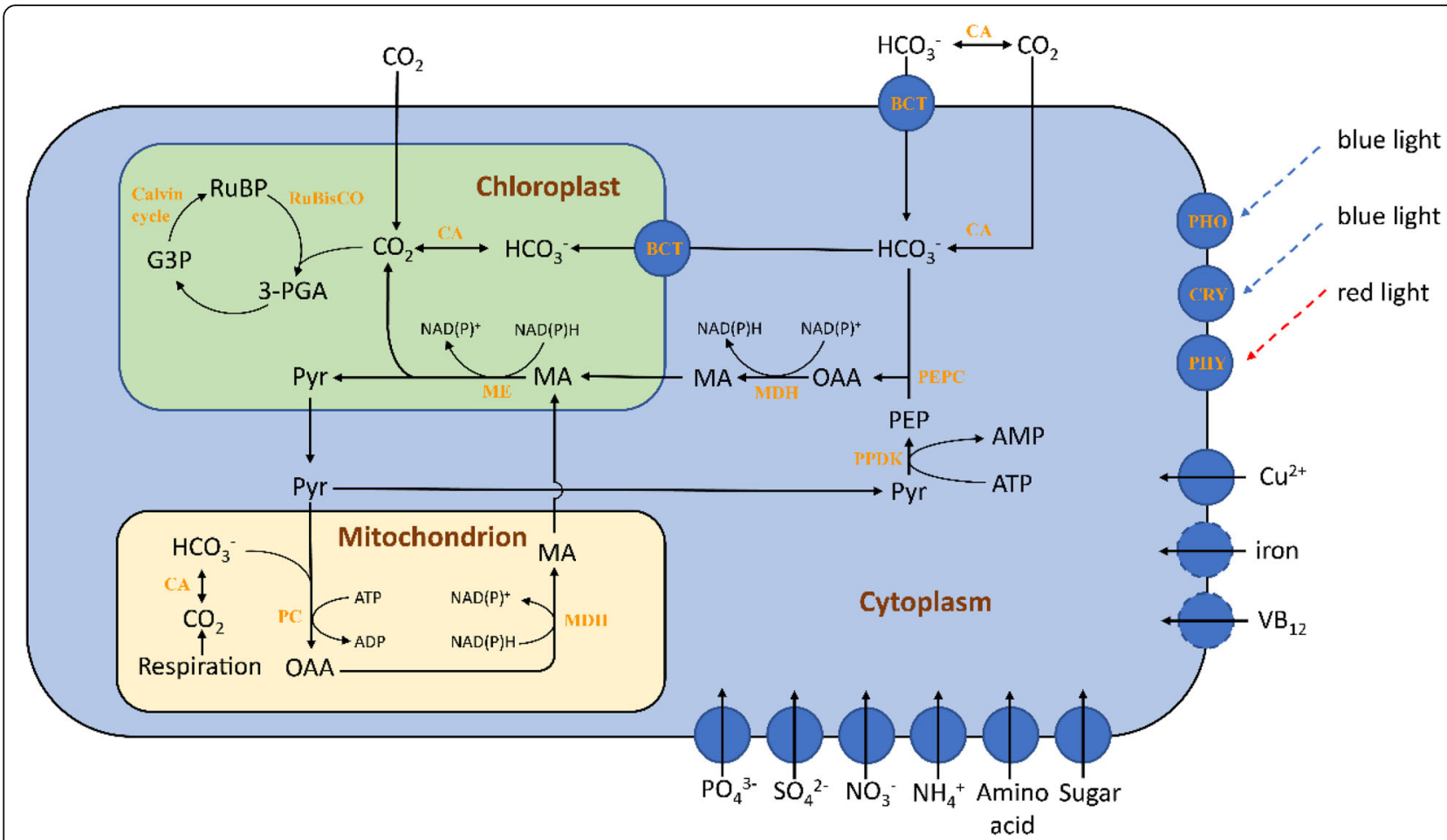

Fig. 10 Carbohydrate metabolism, nutrient transport and photoreceptors in Mychonastes homosphaera. The metabolites are shown in black, and the enzymes are shown in yellow. G3P: glyceraldehyde 3-phosphate, MA: malic acid, OAA: oxaloacetate, PEP: phosphoenolpyruvate, 3-PGA: 3phosphoglycerate, Pyr: pyruvate, RuBP: ribulose-1,5-bisphosphate, BCT: bicarbonate transporter, CA: carbonic anhydrase, MDH: malate dehydrogenase, ME: malic enzyme, PC: pyruvate carboxylase, PEPC: phosphoenolpyruvate carboxylase, PPDK: pyruvate, phosphate dikinase, RuBisCO: ribulose-1,5-bisphosphate carboxylase oxygenase, PHO: phototropins, CRY: cryptochromes, PHY: phytochrome. In nutrient transport, a solid line or circle indicates that the gene has been identified, and a dashed circle indicates that the gene may be present. Metabolic pathway reconstruction was performed based on the KEGG database

\section{Bioenergetic metabolic pathway reconstruction in M.homosphaera \\ Lipid metabolism}

Many microalgae, especially Sphaeropleales species, have been reported to produce considerable amounts of biofuels $[10,11,16]$. Therefore, lipid metabolism pathway reconstruction in M.homosphaera provides essential new insights into the lipid metabolism of phytoplankton and provides a basis for further investigations and genetic improvements. We compiled the genes related to lipid metabolism using the KEGG database to reconstruct the fatty acid biosynthesis pathways and TCA (glycerolipid) metabolism pathways of M.homosphaera. Additionally, we reconstructed the lipid metabolism pathways of other phytoplankton in the same way and compared them with those of M.homosphaera (Fig. 11 and Supplementary Table 8).

M.homosphaera possesses a similar number of genes to other phytoplankton despite its small genome size, and the key fatty acid biosynthesis pathways have been identified. Notably, M.homosphaera exhibited a relatively high number of homologous genes for ACC (acetyl-CoA carboxylase, seven genes) and KAR (3-
oxoacyl-ACP reductase, 11 genes). This situation also exists in other Sphaeropleales species.

Furthermore, the glycerolipid metabolism pathways of M.homosphaera were the same as those of other phytoplankton despite the different genome sizes. TAG (triacylglycerol) can be formed through glycerolipid metabolism via acylCoA-independent or dependent pathways catalyzed by PDAT (phospholipid: diacylglycerol acyltransferase) and DGAT (acyl-CoA:diacylglycerol acyltransferase), respectively. DGAT catalyzes the final step in the acylCoA-dependent pathway, leading to TAG. The DGAT gene family, including DGAT1 and DGAT2, was identified in the past decade [33, 34]. DGAT2 was present in all the phytoplankton that we compared; however, DGAT1 only existed in M.homosphaera and other Sphaeropleales species. PDAT is a key enzyme in the acylCoA-independent pathway and is able to hydrolyze not only phospholipids, cholesteryl esters and galactolipids but also TAG. Therefore, PDAT plays an important role in membrane turnover as well as TAG synthesis and degradation. Although the total genome sizes of M.homosphaera and other picophytoplankton are significantly lower than those 


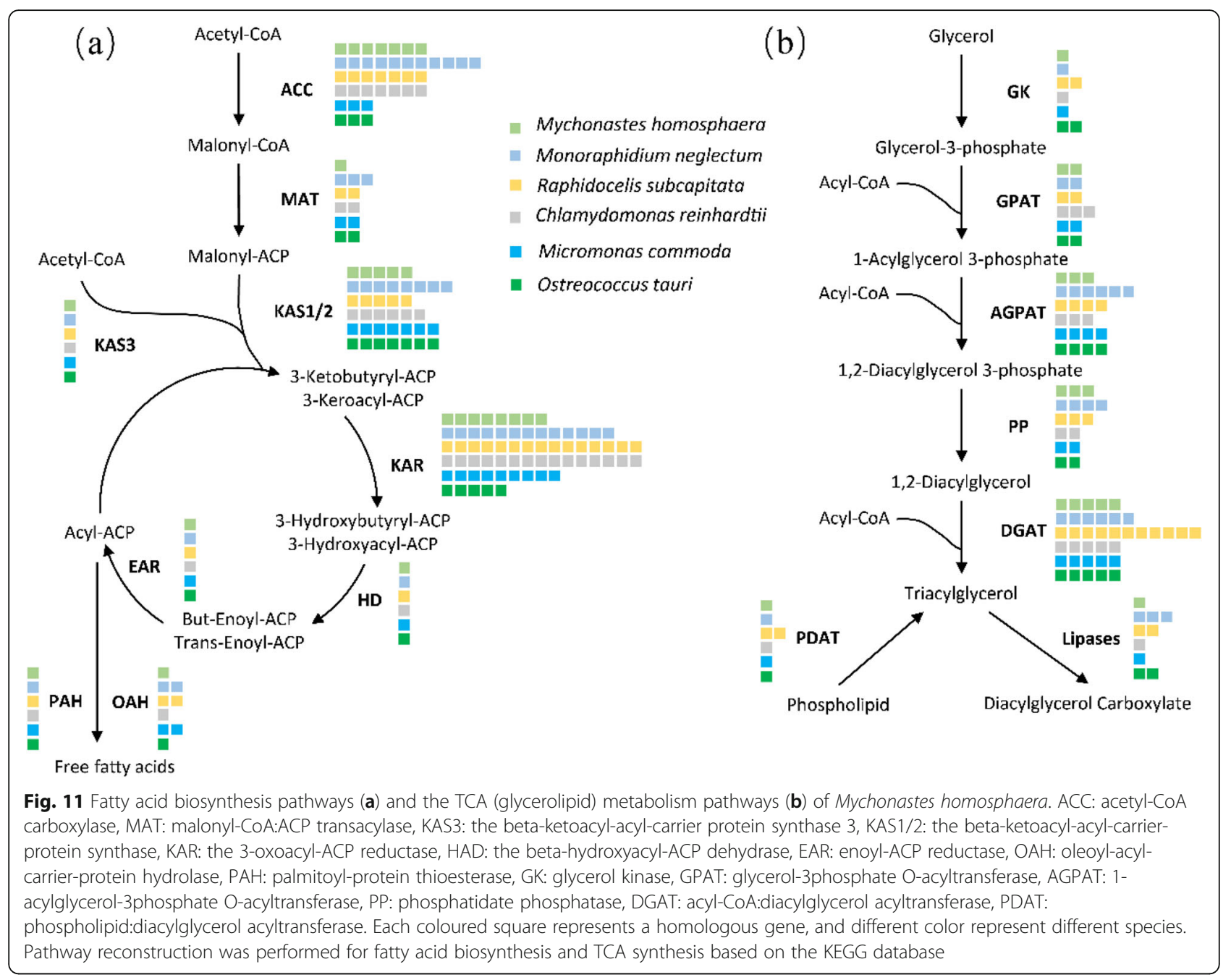

of other phytoplankton, the numbers of genes in glycerolipid metabolism pathways are not significantly different between these groups.

\section{Starch and isoprenoid metabolism}

We analyzed genes related to starch metabolism using the KEGG database and Busi's research [35] to reconstruct the starch metabolism pathways of M.homosphaera (Fig. 12 and Supplementary Table 9). There are four biochemical steps in starch synthesis: substrate activation, chain elongation, chain branching, and chain debranching [36, 37].

There are two isoprenoid biosynthesis pathways found in organisms: the mevalonate (MVA) and the nonmevalonate (DXP) pathways [38]. Similar to other green algae, such as C.reinhardtii, Scenedesmus obliquus and Ostreococcus lucimarinus, M.homosphaera has abandoned the MVA pathway and retained only the DXP pathway (Supplementary Table 10).

\section{Discussion}

\section{Environmental prevalence and adaptation of M.homosphaera}

Understanding the response of this algae to a stressful and fluctuating environment offers the promise of advancing both applied and fundamental research. Mychonastes is a common chlorophycean picoplankton genus in freshwater ecosystems [39] and is widely found in lakes and rivers in Asia [3, 40-42], Europe [43] and North America [44]. Mychonastes species are small (< $3 \mu \mathrm{m}$ ) unicellular organisms (spherical, ovate and ellipsoid) surrounded by a cell wall, possessing one mitochondria and chloroplast. Mychonastes species are prevalent in river-connected lakes where diatoms occur [45], and recent research has shown that Mychonastes is the dominant eukaryotic picophytoplankton group in spring and winter in many eutrophic lakes, such as Lake Chaohu and Lake Poyang $[2,3,40]$. The whole genome of M.homosphaera could provide insight into its adaptive mechanism. 


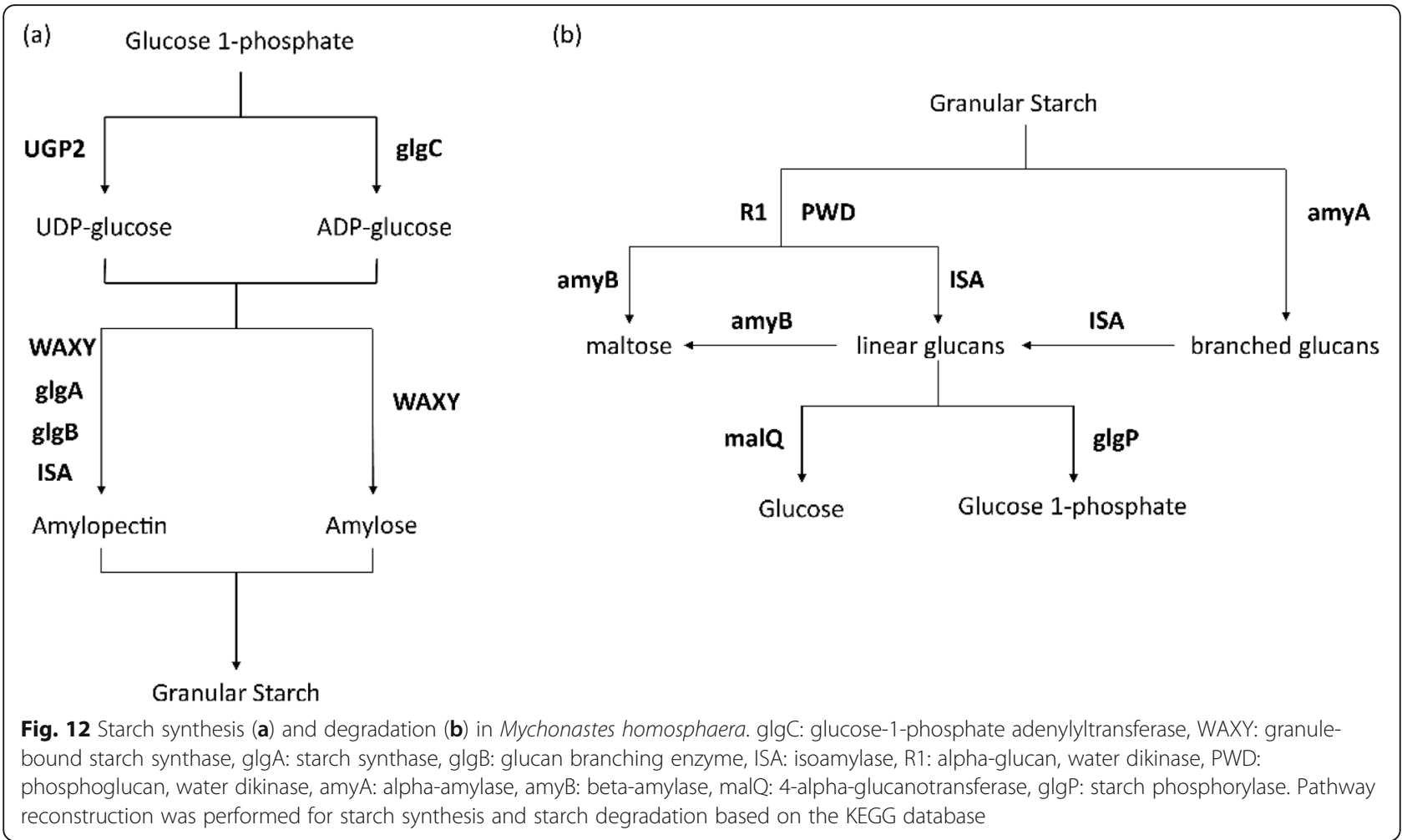

For phytoplankton, only a few resources are potentially limiting, e.g., light, nitrogen, phosphorus, inorganic carbon, silicon, iron, and sometimes a few trace metals or vitamins [46]. M.homosphaera possesses many nutrient transport genes, such as genes encoding nitrogen, phosphorus, metal, and vitamin transporters, that may improve its nutrient uptake ability at a relatively low trophic level. In addition, M.homosphaera could use various sources of nitrogen compounds, strengthening its competitive ability under nutrient-depleted conditions. The presence of various potential carbonconcentrating mechanisms in M.homosphaera would provide more possibilities for carbon assimilation under different environmental conditions. Furthermore, for the supplementation of micronutrient such as metals and vitamins, M.homosphaera possesses its own acquisition pathway.

Light intensity is relatively low and becomes an important limiting factor for phytoplankton growth in spring and winter. M.homosphaera possesses gene homologs of phototropins, cryptochromes and phytochromes, which absorb red light and blue light [47]. Compared with its major counterpart taxon, the diatoms, M.homosphaera lacks rhodopsins, which absorb green light. Red light and blue light are both absorbed at relatively shallow depths, but green light usually penetrates the water column to greater depths than other wavelengths [48]. Thus, the presence of blue/red-light photoreceptors and the absence of green-light photoreceptors increases the adaptation of M.homosphaera to the shallow turbid lake and implies genome streamlining. In addition, the high abundance of light harvesting complex components in M.homosphaera contributes to its adaptation to the low light conditions found in Lake Chaohu in winter.

Light is essential for algae, but excess light will damage the growth of algae. Phytoplankton adjust their light absorption and eliminate excess light energy when light is abundant or excessive [49]. M.homosphaera possesses the light dissipation mechanism of the xanthophyll cycle, which provides the ability to remove accumulated harmful byproducts, such as three line states of chlorophyll molecules and singlet oxygen, resulting from excess light [50]. In addition, the existence of Fe-Mn SODs will decrease the damage caused by reactive oxygen generated by excess light [51].

The water temperatures of Lake Chaohu in winter are normally lower than $10^{\circ} \mathrm{C}$ [40], which is a challenge for phytoplankton growth. To adjust to the winter conditions in the lake, M.homosphaera possesses many mechanisms to respond to low temperatures. M.homosphaera possesses a gene encoding a pyrroline-5-carboxylate reductase that can synthesize proline to alleviate osmotic stress caused by cold. M.homosphaera also possesses genes encoding antioxidases (such as Fe-Mn SOD, catalase, and ascorbate peroxidase) and antioxidant (such as 
glutamate and $\beta$-carotene) biosynthetic pathways. Both of these substances can remove toxic active oxygen derived from excess $\mathrm{O}_{2}$ and $\mathrm{H}_{2} \mathrm{O}_{2}$ in cells under cold stress [52-54]. Unsaturated fatty acids can reduce the phase transition temperature of the plant cytomembrane to prevent plants from being damaged by temperature stress [55-58]. M.homosphaera possesses genes encoding the synthesis of large fatty acids, especially unsaturated fatty acids. The genome sequence of M.homosphaera indicates enrichment of unsaturated fatty acids, which is consistent with other research (more than 70\%) [59]. The high content of unsaturated fatty acids reduces the M.homosphaera phase transition temperature and improves the adaptation of this species in Lake Chaohu. In addition, phytochromes act as temperature sensors that integrate temperature information over the course of the night [60], as warm temperatures reduce the activation of phytochromes, which may improve the adaptation of M.homosphaera to temperature differences between day and night.

Copper deficiency can lead to the inhibition of organism growth, photosynthesis, and respiration. However, excessive copper also has obvious toxic effects on algal bodies, even leading to plant death $[61,62]$. To adapt to an excessive copper environment, M.homosphaera may possess multiple mechanisms for ameliorating copper toxicity. M.homosphaera encodes a phytochelatin synthase that can chelate metal ions to reduce copper toxicity [63] and a Fe-Mn SOD to dispel the free radicals formed due to copper stress [64].

\section{The M.homosphaera genome reveals characteristics suitable for biofuel production}

Algae are also very important because they synthesize a number of different lipids and carbon storage compounds (such as starch and isoprenoid) that possess high biological and commercial value [35]. These characteristics, including high biomass production rates, high starch content and TAG accumulation, make algae a possible biofuel resource. Compared with starch accumulation, Sphaeropleales may show an advantage in TAG accumulation [11].

The complete lipid pathways and abundant homologous gene family in the M.homosphaera genome indicate a high potential lipid yield. Furthermore, the quality of biodiesel is mainly determined by the composition of fatty acids [65]. The abundance of KCS (3-ketoacyl-CoA synthase) and FAD (fatty acid desaturase) homologous genes indicates that M.homosphaera tends to synthesize long-chain unsaturated fatty acids, which are generally well suited for biodiesel generation [66]. In addition, TAG accumulation in phytoplankton usually occurs under stress conditions such as high light or nitrogen starvation [67]. The TAG yield can also be increased artificially by inhibition of starch synthesis [68]. Laboratory experiments revealed that M.homosphaera could have a high growth rate even under environmental stress [69]. In addition to the high specific uptake rate of $\mathrm{CO}_{2}$, M.homosphaera is capable of utilizing polysaccharides as a carbon source. Therefore, extensive carbon sources, efficient photosynthesis, rapid growth and lipid abundance indicate that M.homosphaera could be a preferred source for biodiesel production. Environmental condition control and biotechnological applications to improve the yield and quality of TAG would make M.homosphaera more appropriate to biodiesel production.

\section{Genome streamlining of M.homosphaera}

It is commonly believed that evolution generally proceeds towards increased complexity at both the genomic and organismal levels. However, recent evolutionary reconstructions indicate that genome reduction is a dominant mode of genome evolution, consistent with the optimization of initially highly complex large genomes, leading to the acquisition of adaptive innovations [70]. M.homosphaera and other picophytoplankton, such as Ostreococcus tauri and Micromonas commoda, possess smaller and more streamlined genomes than phytoplankton of the same genus. Streamlined genomes are characteristic of fast-evolving species that live in specialized ecological niches or in extreme environments [71]. The whole-genome analysis suggested that there are two routes for genome reduction in M.homosphaera, namely, the reduction of gene family number and of noncoding region (intergenic and intron) size. Although M.homosphaera possesses the minimum number of gene families in the order Sphaeropleales, this species has retained all the fundamental functional genes and can grow well in uni-algal laboratory experiments [69]. In addition, M.homosphaera possesses nearly the most dense nuclear genome (24.23 Mb) in Chlorophyceae, second only to R.subcapitata, with mean intergenic and intron lengths of 685 and $359 \mathrm{bp}$, respectively. This streamlining is particularly obvious in organelle genomes, including those of chloroplasts and mitochondria. M.homosphaera have the highest protein coding density among Sphaeropleales, and these genomes do not contain introns, leading to the reduction in organelle genomes. This compact nuclear genome has also been found in other picophytoplankton, such as O.tauri and M.commoda, although their genetic relationships are relatively distant. This result may indicate that the genome architecture is consistent with cell size in phytoplankton, although the relationship between the genome architecture and cell size remains controversial [72-74]. Such streamlined genomes are also detectable in the cyanobacterium Prochlorococcus sp. $[75,76]$ and the alpha-proteobacterium Candidatus Pelagibacter ubique [77-79], both of which are highly successful free-living organisms and apparently the most abundant cellular life forms on earth. 


\section{M.homosphaera genomes provide insights into evolutionary processes}

Previous research indicates that the algae in Sphaeropleales harbor split cox2 genes, including a mitochondrion-localized cox $2 \mathrm{a}$ gene and a nucleuslocalized cox2b gene [80]. Consistent with this finding, M.homosphaera harbored split cox2 genes, comprising a mitochondrion-localized cox $2 \mathrm{a}$ gene and a nucleuslocalized cox $2 b$ gene. However, Prasinophyceae, Ulvophyceae and Trebouxiophyceae contain orthodox, intact, mitochondrial cox 2 genes, having evolved earlier than Chlamydomonadales, which possess both split cox2 genes in their nuclear genome [81]. Sphaeropleales show an intermediate trait of gene migration to the nucleus, which indicates that the appearance of Sphaeropleales occurred between that of Ulvophyceae and Chlamydomonadales.

In addition, the presence of NUMTs (nuclear mitochondrial DNA) and NUPTs (nuclear plastid DNA) (Supplementary Text, Supplementary Table 11 and 12) in M.homosphaera genomes verified gene migration from organelles to the nucleus. This is an important process for genome streamlining in most eukaryotes [82], as migrated genes are usually inserted into the intergenic space of the nuclear genome to improve the coding rate of the nuclear genome. During the evolution of mitochondria, many mitochondrial genes have been functionally transferred to the nucleus, whereas others have been replaced by preexisting nuclear genes which possessed similar function [83].

The Endosymbiotic Hypothesis is a hypothesis about the origins of mitochondria and chloroplasts, which are organelles of eukaryotic cells. According to this, land plants and green algae acquired their plastids from the same endosymbiotic event, the Glaucophyta and red algae (Rhodophyta), likely also originated from secondary endosymbiosis [84]. The DXP pathway is provided by the eukaryotic host cell during the primary endosymbiotic event in phototrophs with primary plastids. In contrast, the MVA pathway is contributed by the secondary eukaryotic host, with possible contributions from the primary host cell in algal groups emerging from secondary endosymbiosis [85]. Similar to other green algae, such as C.reinhardtii, S.obliquus and O.lucimarinus, M.homosphaera had abandoned the MVA pathway and retained only the DXP pathway [24]. However, the primary endosymbiotic algal groups Glaucophyta and Rhodophyta (except C.merolae) and secondary endosymbiotic algal groups Euglenophyta, Chlorarachniophyta, Haptophyta and Heterokontophyta have maintained both the MVA and DXP pathways. Therefore, the abandonment of the MVA pathway and the presence of the DXP pathway in M.homosphaera could support the endosymbiosis hypothesis.

\section{Conclusions}

This study focused on the analysis of the whole genome of M.homosphaera, a eukaryotic picophytoplankton, providing insights into the environmental adaptation mechanism of these organisms, including efficient and comprehensive nutrient utilization capacity, a special light harvesting system to adapt to low light conditions, a multifarious defense mechanism against coldness, and various response mechanisms to improve resistance to environmental stress. In addition, M.homosphaera exhibits high lipid yields, particularly of long-chain unsaturated fatty acids. Therefore, this species is generally well suited for biodiesel generation. Similar to other picophytoplankton, streamlining and genome compaction was observed for M.homosphaera Streamlining of the genome of M.homosphaera may be caused by the reduction in gene family number and noncoding region size. With respect to genetic evolution, the split cox2 genes in M.homosphaera indicate gene migration from the organelles to the nucleus and the abandonment of the MVA pathway, and the presence of the DXP pathway in M.homosphaera could support the endosymbiosis hypothesis.

\section{Methods}

\section{Isolation and culture of M.homosphaera}

M.homosphaera was isolated from the central region Lake Chaohu $\left(31.5294^{\circ} \mathrm{N}, 117.5261^{\circ} \mathrm{E}\right)$ in December 2015 , and preserved in our laboratory at the Nanjing Institute of Geography and Limnology, Chinese Academy of Sciences. The strain was cultivated at $15^{\circ} \mathrm{C}$ in BG11 medium under light (12 h light:12 h dark; $25 \mu \mathrm{mol}$ photo $\mathrm{m}^{-2} \mathrm{~s}^{-1}$ ) in 250-mL glass flasks.

\section{DNA extraction}

M.homosphaera was collected, and genomic DNA was extracted by using the QIAGEN Genomic DNA Extraction Kit (Cat\# 13323, QIAGEN) according to the standard operating procedure provided by the manufacturer. The extracted DNA was detected by a NanoDrop ${ }^{\mathrm{TM}}$ One UV-Vis spectrophotometer (Thermo Fisher Scientific, USA) for DNA purity (OD260/280 ranging from 1.8 to 2.0 and OD 260/230 is between 2.0 and 2.2), and then, a Qubit 3.0 fluorometer (Invitrogen, USA) was used to quantify the DNA accurately.

\section{Library construction and sequencing}

After the sample was qualitatively analyzed, the genomic DNA was sheared by using g-TUBEs (Covaris, USA) according to the expected sizes of the fragments for the library. The fragmented DNA of the target size was enriched and purified by using MegBeads. Next, the fragmented DNA was repaired for damage and then end-repaired. The stem-loop adaptor was linked on both 
ends of each DNA fragment, and the link-failed fragments were removed by exonuclease. Then, the target fragments were screened by BluePippin (Sage Science, USA) and purified to construct the library. Finally, an Agilent 2100 Bioanalyzer (Agilent Technologies, USA) was used to determine the sizes of the library fragments.

After the library was constructed, DNA templates and enzyme complexes of a certain concentration and volume were transferred to the ZMWs of the Sequel system (Pacific Biosciences, USA) for real-time single-molecule sequencing.

\section{Assembly and annotation}

A total of $5.8 \mathrm{G}$ high-quality subreads were generated with a mean length of $6.6 \mathrm{~kb}$ and subreads N50 $9.8 \mathrm{~kb}$ (Fig. 13). For genome assembly, the subreads were first rectified with canu [86] to obtain trimmed reads, and Wtdbg (https://github.com/ruanjue/wtdbg) was used to perform assembly based on these trimmed reads. The draft assembly contigs were then corrected using Pacbio reads with Quiver [87]. Then, the quivered contigs were further polished with Illumina reads by using Pilon [88]. Finally, the corrected genomic sequence was aligned to the nt database (Nucleotide Sequence Database, ftp://ftp. ncbi.nih.gov/blast/db), and the relevant plant, algae and no-hit sequences were retained. The final assembly genome was $24.23 \mathrm{Mb}$ with contig N50 $2 \mathrm{Mb}$, contig number 31. Length of the longest sequence is 2,973,032 bp, and 12 contigs make up for $90 \%$ of the total genome. BUSCO [89] analysis showed that $89.4 \%$ of the 303 core genes in the eukaryote dataset were complete (Supplementary Table 1), which indicated that most highly conserved genomes were well packed and that the assembly results were reliable.

The interspersed repetitive sequences were predicted using MISA [90]. Two strategies were adopted to annotate repetitive sequences: RepeatMask based on aligning with a database or RepeatModeler [91] based on constructing a de novo repeat database. For gene structure annotation, the de novo prediction method Augustus [92]; homology alignment prediction, such as with GeneWise [93] and EST/cDNA; and genome alignment prediction approach, including PASA [94], were used separately and integrated through EVM [94]. Transposon PSI [95] alignment was performed to remove genes containing transposable elements.

The predicted protein sequences were searched against KEGG, COG (Cluster of Orthologous Groups), NR (Non-Redundant Protein Database), Trembl and Swissprot to predict gene functions and metabolic information through Blastall [94]. A whole-genome blast was performed against the secondary database InterPro to predict conserved sequences and domains of proteins using InterProScan [96]. For noncoding RNA

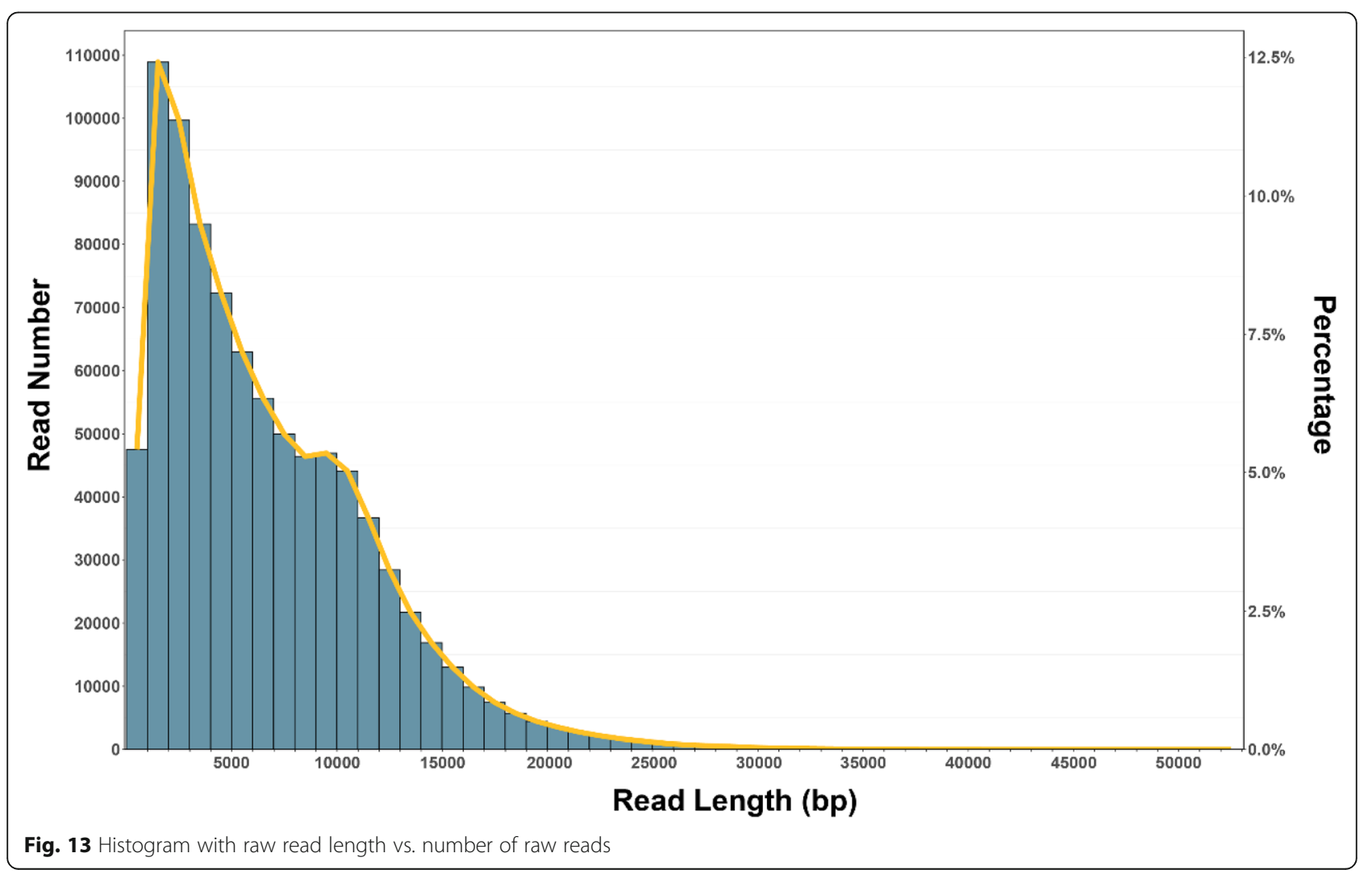


annotation, both strategies, including alignment with the existing noncoding RNA database Rfam [97] and predictions with tRNAscan-SE [98] or RNAmmer [99], were adopted. The major software program versions and parameter settings has been described in the Supplementary Table 13.

This Whole Genome Shotgun project has been deposited at DDBJ/ENA/GenBank under the accession VXJC00000000. The version described in this paper is version VXJC01000000. Gene annotation file and the gene set files have been provided as supplementary files (Supplementary file 1, 2 and 3). And the PacBio data has been deposited at NCBI under BioProject number PRJNA556117.

\section{Phylogenetic analysis}

We investigated the phylogenetic position of M.homosphaera by using $18 \mathrm{~S}$ rDNA, which is a widely used molecular barcode for taxonomic affiliation in phytoplankton [100]. The analysis involved 18 nucleotide sequences from NCBI (Supplementary Table 14), and all positions containing gaps and missing data were eliminated. There were a total of 1765 positions in the final data set. Maximum likelihood (ML) analysis was conducted based on the Tamura-Nei model [101] in MEGA $X$ [102], with 1000 bootstrap repetitions.

\section{Drawing tool}

OrganellarGenomeDRAW 1.3.1 was used to generate Figs. 3 and 4. and Adobe Illustrator CS6 was used to generate other figures.

\section{Supplementary information}

Supplementary information accompanies this paper at https://doi.org/10. 1186/s12864-020-06891-6.

Additional file 1: Supplementary Table 1. BUSCO forecast statistics. Supplementary Table 2. SSR classification statistics. Supplementary Table 3. List of conserved genes in chloroplast. Supplementary Table 4. List of conserved genes in mitochondria. Supplementary Table 5. carbon meth genes. Supplementary Table 6. Genes involved in nitrogen assimilation up to ammonium. Supplementary Table $\mathbf{7 .}$ Thiamine biosynthesis genes. Supplementary Table 8. Lipid metabolic gene comparison. Supplementary Table 9. Starch biosynthesis genes. Supplementary Table 10. non-mevalonate pathway (DXP) genes. Supplementary Table 11. NUMTs List of Mychonastes sp. and other phytoplankton. Supplementary Table 12. NUPTs List of Mychonastes sp. and other phytoplankton. Supplementary Table 13. The versions of major software and database. Supplementary Table 14. Sources of $18 \mathrm{~S}$ rDNA sequences. Supplementary Table 15. Sources of genomic sequences.

\section{Abbreviations}

BUSCOs: Benchmarking Universal Single-Copy Orthologs;: SSR: Simple sequence repeat; CDS: Coding sequence; ORF: Open reading frame; GO: Gene ontology; KEGG: Kyoto Encyclopedia of Genes and Genomes; VDE: Violaxanthin de-epoxidase; ZE: Zeaxanthin epoxidase; SOD: Superoxide dismutase; LHC: Light-harvesting complex; ZIP: Zrt, Irt-like protein; $V_{12}$ : Vitamin B12; TCA: Glycerolipid; ACC: Acetyl-CoA carboxylase; KAR: 3Oxoacyl-ACP reductase; TAG: Triacylglycerol;
PDAT: Phospholipid:diacylglycerol acyltransferase; DGAT: AcylCoA:diacylglycerol acyltransferase; MVA: Mevalonate pathway; DXP: Nonmevalonate pathway; KCS: 3-Ketoacyl-CoA synthase; FAD: Fatty acid desaturase

\section{Acknowledgements}

We would like to thank MetaBio Science \&Technology Co. Ltd. (Wuxi, China), which provided sequencing services.

\section{Authors' contributions}

$\mathrm{CL}$ and XS contributed the central idea, analyzed most of the data, and wrote the initial draft of the paper. FW and MR performed the experiment. GG and QW carried out additional analyses and finalized this paper. All authors have read and approved the manuscript.

\section{Funding}

This research was supported by the National Natural Science Foundation of China (31670462, 31730013 and 41877544) and the "One-Three-Five" Strategic Planning of Nanjing Institute of Geography and Limnology, Chinese Academy of Sciences (Grant No. NIGLAS2017GH05). Those funding supported the sample collection and sequencing. The Investigation of Basic Science and Technology Resources (2017FY100300), the Taihu Lake water pollution control special funds (TH2018402) and Chinese Academy of Sciences (qyzdj-ssw-dqc030) financially sponsored the data analysis of this work.

\section{Availability of data and materials}

The datasets generated during the current study are available in the NCBI repository under the accession VXJC00000000. And accession numbers of the reference datasets such as the nucleotide sequences and genomic sequences form NCBI repository had been listed in the Supplementary Table 14 and 15.

Ethics approval and consent to participate Not applicable.

\section{Consent for publication}

Not applicable.

\section{Competing interests}

The authors declare that they have no competing interests.

\section{Author details}

'State Key Laboratory of Lake Science and Environment, Nanjing Institute of Geography and Limnology, Chinese Academy of Sciences, Nanjing 210008, China. ${ }^{2}$ University of Chinese Academy of Sciences, Beijing 100049, China.

Received: 6 November 2019 Accepted: 7 July 2020

Published online: 11 July 2020

\section{References}

1. Sieburth JM, Smetacek V, Lenz J. Pelagic ecosystem structure: heterotrophic compartments of the plankton and their relationship to plankton size fractions - comment. Limnol Oceanogr. 1978;23(6):1256-63.

2. Li S, Shi X, Lepère $C$, Liu M, Wang $X$, Kong F. Unexpected predominance of photosynthetic picoeukaryotes in shallow eutrophic lakes. J Plankton Res. 2016;38(4):830-42.

3. Shi X, Li S, Fan F, Zhang M, Yang Z, Yang Y. Mychonastes dominates the photosynthetic picoeukaryotes in Lake Poyang, a river-connected lake. FEMS Microbiol Ecol. 2019;95(1):fiy211.

4. Gobler CJ, Berry DL, Dyhrman ST, Wilhelm SW, Salamov A, Lobanov AV, Zhang Y, Collier JL, Wurch LL, Kustka AB, et al. Niche of harmful alga Aureococcus anophagefferens revealed through ecogenomics. Proc Natl Acad Sci U S A. 2011;108(11):4352-7.

5. Parker MS, Mock T, Armbrust EV. Genomic insights into marine microalgae. Annu Rev Genet. 2008:42:619-45.

6. Schuster SC. Next-generation sequencing transforms today's biology. Nat Methods. 2008:5(1):16-8.

7. Metzker ML. Sequencing technologies - the next generation. Nat Rev Genet. 2010;11(1):31-46. 
8. Goodwin S, McPherson JD, McCombie WR. Coming of age: ten years of nextgeneration sequencing technologies. Nat Rev Genet. 2016;17(6):333-51.

9. Dasgupta CN, Nayaka S, Toppo K, Singh AK, Deshpande U, Mohapatra A. Draft genome sequence and detailed characterization of biofuel production by oleaginous microalga Scenedesmus quadricauda LWG002611. Biotechnol Biofuels. 2018;11:308.

10. Suzuki S, Yamaguchi H, Nakajima N, Kawachi M. Raphidocelis subcapitata (= Pseudokirchneriella subcapitata) provides an insight into genome evolution and environmental adaptations in the Sphaeropleales. Sci Rep. 2018;8:8058.

11. Bogen C, Al-Dilaimi A, Albersmeier A, Wichmann J, Grundmann M, Rupp O, Lauersen KJ, Blifernez-Klassen O, Kalinowski J, Goesmann A, et al. Reconstruction of the lipid metabolism for the microalga Monoraphidium neglectum from its genome sequence reveals characteristics suitable for biofuel production. BMC Genomics. 2013;14:926.

12. Carreres BM, de Jaeger L, Springer J, Barbosa MJ, Breuer G, van den End EJ, Kleinegris DMM, Schaffers I, Wolbert EJH, Zhang H, et al. Draft Genome Sequence of the Oleaginous Green Alga Tetradesmus obliquus UTEX 393. Genome Announc. 2017;5(3):e01449-16.

13. Derelle E, Ferraz C, Rombauts S, Rouze P, Worden AZ, Robbens S, Partensky F, Degroeve $S$, Echeynie $S$, Cooke $R$, et al. Genome analysis of the smallest free-living eukaryote Ostreococcus tauri unveils many unique features. Proc Natl Acad Sci U S A. 2006;103(31):11647-52.

14. van Baren MJ, Bachy C, Reistetter EN, Purvine SO, Grimwood J, Sudek S, Yu H, Poirier C, Deerinck TJ, Kuo A, et al. Evidence-based green algal genomics reveals marine diversity and ancestral characteristics of land plants. BMC Genomics. 2016;17:267.

15. Wolf M, Buchheim M, Hegewald E, Krienitz L, Hepperle D. Phylogenetic position of the Sphaeropleaceae (Chlorophyta). Plant Syst Evol. 2002;230(34):161-71.

16. Mandal S, Mallick N. Microalga Scenedesmus obliquus as a potential source for biodiesel production. Appl Microbiol Biotechnol. 2009;84(2):281-91.

17. Roth MS, Cokus SJ, Gallaher SD, Walter A, Lopez D, Erickson E, Endelman B, Westcott D, Larabell CA, Merchant SS, et al. Chromosome-level genome assembly and transcriptome of the green alga Chromochloris zofingiensis illuminates astaxanthin production. Proc Natl Acad Sci U S A. 2017;114(21):E4296-305.

18. Karpagam R, Jawaharraj K, Ashokkumar B, Sridhar J, Varalakshmi P. Unraveling the lipid and pigment biosynthesis in Coelastrella sp M-60: genomics-enabled transcript profiling. Algal Res Biomass Biofuels Bioproducts. 2018;29:277-89.

19. Hanagata N, Malinsky-Rushansky N, Dubinsky Z. Eukaryotic picoplankton, Mychonastes homosphaera (Chlorophyceae, Chlorophyta), in Lake Kinneret, Israel. Phycol Res. 1999;47(4):263-9.

20. Armbrust EV, Berges JA, Bowler C, Green BR, Martinez D, Putnam NH, Zhou $\mathrm{SG}$, Allen AE, Apt KE, Bechner M, et al. The genome of the diatom Thalassiosira pseudonana: ecology, evolution, and metabolism. Science. 2004;306(5693):79-86.

21. Demmig B, Winter K, Kruger A, Czygan FC. Photoinhibition and Zeaxanthin formation in intact leaves -a possible role of the xanthophyll cycle in the dissipation of excess light energy. Plant Physiol. 1987;84(2):218-24.

22. Pinnola A, Dall'Osto L, Gerotto C, Morosinotto T, Bassi R, Alboresi A. Zeaxanthin binds to light-harvesting complex stress-related protein to enhance nonphotochemical quenching in Physcomitrella patens. Plant Cell. 2013:25(9):3519-34.

23. Reinfelder JR. Carbon Concentrating Mechanisms in Eukaryotic Marine Phytoplankton. In: Carlson CA, Giovannoni SJ, editors. Annual Review of Marine Science, Vol 3; 2011. p. 291-315.

24. Radakovits R, Jinkerson RE, Fuerstenberg SI, Tae H, Settlage RE, Boore JL, Posewitz MC. Draft genome sequence and genetic transformation of the oleaginous alga Nannochloropis gaditana. Nat Commun. 2012;3:10.

25. Palenik B, Grimwood J, Aerts A, Rouze P, Salamov A, Putnam N, Dupont C, Jorgensen $R$, Derelle $E$, Rombauts $S$, et al. The tiny eukaryote Ostreococcus provides genomic insights into the paradox of plankton speciation. Proc Natl Acad Sci U S A. 2007;104(18):7705-10

26. Klaumann S, Nickolaus SD, Fuerst SH, Starck S, Schneider S, Neuhaus HE, Trentmann O. The tonoplast copper transporter COPT5 acts as an exporter and is required for interorgan allocation of copper in Arabidopsis thaliana. New Phytol. 2011;192(2):393-404.

27. Pilon M. Moving copper in plants. New Phytol. 2011;192(2):305-7.

28. Helliwell KE, Wheeler GL, Leptos KC, Goldstein RE, Smith AG. Insights into the evolution of vitamin B-12 Auxotrophy from sequenced algal genomes, Mol Biol Evol. 2011;28(10):2921-33.
29. Croft MT, Warren MJ, Smith AG. Algae need their vitamins. Eukaryot Cell. 2006;5(8):1175-83.

30. Croft MT, Lawrence AD, Raux-Deery E, Warren MJ, Smith AG. Algae acquire vitamin B-12 through a symbiotic relationship with bacteria. Nature. 2005; 438(7064):90-3.

31. Boubakri H, Gargouri M, Mliki A, Brini F, Chong J, Jbara M. Vitamins for enhancing plant resistance. Planta. 2016;244(3):529-43.

32. Rapala-Kozik M, Wolak N, Kujda M, Banas AK. The upregulation of thiamine (vitamin B-1) biosynthesis in Arabidopsis thaliana seedlings under salt and osmotic stress conditions is mediated by abscisic acid at the early stages of this stress response. BMC Plant Biol. 2012;12:2.

33. Lardizabal KD, Mai JT, Wagner NW, Wyrick A, Voelker T, Hawkins DJ. DGAT2 is a new diacylglycerol acyltransferase gene family - purification, cloning, and expression in insect cells of two polypeptides from Mortierella ramanniana with diacylglycerol acyltransferase activity. J Biol Chem. 2001; 276(42):38862-9.

34. Yen C-LE, Stone SJ, Koliwad S, Harris C, Farese RV Jr. DGAT enzymes and triacylglycerol biosynthesis. J Lipid Res. 2008;49(11):2283-301.

35. Busi MV, Barchiesi J, Martin M, Gomez-Casati DF. Starch metabolism in green algae. Starch-Starke. 2014;66(1-2):28-40.

36. Zeeman SC, Kossmann J, Smith AM. Starch: Its Metabolism, Evolution, and Biotechnological Modification in Plants. In: Merchant S, Briggs WR, Ort D, editors. Annual Review of Plant Biology, Vol 61; 2010. p. 209-34.

37. Preiss J, Ball K, Smithwhite B, Iglesias A, Kakefuda G, Li L. Starch biosynthesis and its regulation. Biochem Soc Trans. 1991;19(3):539-47.

38. Eisenreich W, Bacher A, Arigoni D, Rohdich F. Biosynthesis of isoprenoids via the non-mevalonate pathway. Cell Mol Life Sci. 2004;61(12):1401-26.

39. Krienitz L, Bock C, Dadheech PK, Proeschold T. Taxonomic reassessment of the genus Mychonastes (Chlorophyceae, Chlorophyta) including the description of eight new species. Phycologia. 2011:50(1):89-106.

40. Li S, Bronner G, Lepere C, Kong F, Shi X. Temporal and spatial variations in the composition of freshwater photosynthetic picoeukaryotes revealed by MiSeq sequencing from flow cytometry sorted samples. Environ Microbiol. 2017:19(6):2286-300

41. Hanagata N, Malinsky-Rushansky N, Dubinsky Z. Eukaryotic picoplankton, Mychonastes homosphaera (Chlorophyceae, Chlorophyta), in Lake Kinneret, Israel. Phycol Res. 2010;47(4):263-9.

42. $W u L, X u L, H u C$. Screening and characterization of oleaginous microalgal species from northern Xinjiang. J Microbiol Biotechnol. 2015;25(6):910-7.

43. Hepperle D, Schlegel I. Molecular diversity of eucaryotic picoalgae from three lakes in Switzerland. Int Rev Hydrobiol. 2002;87(1):1-10.

44. Phillips KA, Fawley MW. Diversity of coccoid algae in shallow lakes during winter. Phycologia. 2000;39(6):498-506.

45. Reynolds CS, Descy JP, Padisak J. Are phytoplankton dynamics in rivers so different from those in shallow lakes? Hydrobiologia. 1994;289(1-3):1-7.

46. Huisman J, Weissing FJ. Biodiversity of plankton by species oscillations and chaos. Nature. 1999:402(6760):407-10.

47. Hegemann P. Algal sensory photoreceptors. Annu Rev Plant Biol. 2008:59: 167-89.

48. Hamilton DP, Collier KJ, Quinn JM, Howard-Williams C. Lake restoration handbook: a New Zealand perspective. Cham: Springer; 2018.

49. Li Z, Wakao S, Fischer BB, Niyogi KK. Sensing and responding to excess light. Annu Rev Plant Biol. 2009:60:239-60.

50. Walters RG. Towards an understanding of photosynthetic acclimation. J Exp Bot. 2005:56(411):435-47.

51. Mittler R. Oxidative stress, antioxidants and stress tolerance. Trends Plant Sci. 2002;7(9):405-10.

52. Van Breusegem F, Slooten L, Stassart JM, Botterman J, Moens T, Van Montagu M, Inze D. Effects of overproduction of tobacco MnSOD in maize chloroplasts on foliar tolerance to cold and oxidative stress. J Exp Bot. 1999; 50(330):71-8.

53. Fryer MJ, Andrews JR, Oxborough K, Blowers DA, Baker NR. Relationship between $\mathrm{CO} 2$ assimilation, photosynthetic electron transport, and active O2 metabolism in leaves of maize in the field during periods of low temperature. Plant Physiol. 1998;116(2):571-80

54. Prasad TK. Role of catalase in inducing chilling tolerance in pre-emergent maize seedlings. Plant Physiol. 1997;114(4):1369-76.

55. Lyons JM. Chilling injury in plants. Annu Rev Plant Physiol Plant Mol Biol. 1973;24:445-66.

56. Murata N, Los DA. Membrane fluidity and temperature perception. Plant Physiol. 1997;115(3):875-9. 
57. Nishida I, Murata N. Chilling sensitivity in plants and cyanobacteria: the crucial contribution of membrane lipids. Annu Rev Plant Physiol Plant Mol Biol. 1996:47:541-68.

58. Somerville C. Direct tests of the role of membrane lipid composition in lowtemperature-induced photoinhibition and chilling sensitivity in plants and cyanobacteria. Proc Natl Acad Sci U S A. 1995;92(14):6215-8.

59. Yuan C, Liu J, Fan Y, Ren X, Hu G, Li F. Mychonastes afer HSO-3-1 as a potential new source of biodiesel. Biotechnol Biofuels. 2011;4:47. https://doi. org/10.1186/1754-6834-1184-1147.

60. Jung JH, Domijan M, Klose C, Biswas S, Ezer D, Gao MJ, Khattak AK, Box MS, Charoensawan V, Cortijo S, et al. Phytochromes function as thermosensors in Arabidopsis. Science. 2016;354(6314):886-9.

61. Fawaz EG, Salam DA, Kamareddine L. Evaluation of copper toxicity using site specific algae and water chemistry: field validation of laboratory bioassays. Ecotoxicol Environ Saf. 2018;155:59-65.

62. Wang $H$, Ebenezer V, Ki J-S. Photosynthetic and biochemical responses of the freshwater green algae Closterium ehrenbergii Meneghini (Conjugatophyceae) exposed to the metal coppers and its implication for toxicity testing. J Microbiol. 2018;56(6):426-34.

63. Ahner BA, Morel FMM. Phytochelatin production in marine algae. 2 . Induction by various metals. Limnol Oceanogr. 1995;40(4):658-65.

64. Alscher RG, Erturk N, Heath LS. Role of superoxide dismutases (SODs) in controlling oxidative stress in plants. J Exp Bot. 2002:53(372):1331-41.

65. Mukta N, Murthy IYLN, Sripal P. Variability assessment in Pongamia pinnata (L.) Pierre germplasm for biodiesel traits. Ind Crop Prod. 2009;29(2-3): 536-40

66. Ramos MJ, Fernandez CM, Casas A, Rodriguez L, Perez A. Influence of fatty acid composition of raw materials on biodiesel properties. Bioresour Technol. 2009;100(1):261-8.

67. Hu Q, Sommerfeld M, Jarvis E, Ghirardi M, Posewitz M, Seibert M, Darzins A. Microalgal triacylglycerols as feedstocks for biofuel production: perspectives and advances. Plant J. 2008:54(4):621-39.

68. Li Y, Han D, Hu G, Sommerfeld M, Hu Q. Inhibition of starch synthesis results in overproduction of lipids in Chlamydomonas reinhardtii. Biotechnol Bioeng. 2010;107(2):258-68

69. Liu C, Shi X, Fan F, Wu F, Lei J. N:P ratio influences the competition of Microcystis with its picophytoplankton counterparts, Mychonastes and Synechococcus, under nutrient enrichment conditions. J Freshwat Ecol. 2019;34(1):445-54.

70. Wolf Yl, Koonin EV. Genome reduction as the dominant mode of evolution. Bioessays. 2013;35(9):829-37.

71. Giovannoni SJ, Thrash JC, Temperton B. Implications of streamlining theory for microbial ecology. ISME J. 2014;8(8):1553-65.

72. Lynch M, Conery JS. The origins of genome complexity. Science. 2003; 302(5649):1401-4

73. Lynch M. Streamlining and simplification of microbial genome architecture. In: Annu Rev Microbiol vol 60; 2006. p. 327-49.

74. Smith DR, Hamaji T, Olson BJSC, Durand PM, Ferris P, Michod RE, Featherston J, Nozaki H, Keeling PJ. Organelle genome complexity scales positively with organism size in Volvocine Green algae. Mol Biol Evol. 2013; 30(4):793-7.

75. Partensky F, Garczarek L. Prochlorococcus: advantages and limits of minimalism. Annu Rev Mar Sci. 2010;2:305-31.

76. Dufresne A, Garczarek L, Partensky F. Accelerated evolution associated with genome reduction in a free-living prokaryote. Genome Biol. 2005:6(2):R14.

77. Morris JJ, Lenski RE, Zinser ER. The Black Queen Hypothesis: Evolution of Dependencies through Adaptive Gene Loss. Mbio. 2012;3(2):e00036-12.

78. Giovannoni SJ, Tripp HJ, Givan S, Podar M, Vergin KL, Baptista D, Bibbs L, Eads J, Richardson TH, Noordewier M, et al. Genome streamlining in a cosmopolitan oceanic bacterium. Science. 2005;309(5738):1242-5.

79. Viklund J, Ettema TJG, Andersson SGE. Independent genome reduction and phylogenetic reclassification of the oceanic SAR11 clade. Mol Biol Evol. 2012;29(2):599-615.

80. Rodriguez-Salinas E, Riveros-Rosas H, Li Z, Fucikova K, Brand JJ, Lewis LA, Gonzalez-Halphen D. Lineage-specific fragmentation and nuclear relocation of the mitochondrial cox2 gene in chlorophycean green algae (Chlorophyta). Mol Phylogenet Evol. 2012;64(1):166-76.

81. Perez-Martinez X, Antaramian A, Vazquez-Acevedo M, Funes S, Tolkunova E, d'Alayer J, Claros MG, Davidson E, King MP, Gonzalez-Halphen D. Subunit II of cytochrome c oxidase in chlamydomonad algae is a heterodimer encoded by two independent nuclear genes. J Biol Chem. 2001;276(14): 11302-9.

82. Blanchard $J$, Schmidt GW. Pervasive migration of organellar DNA to the nucleus in plants. J Mol Evol. 1995;41(4):397-406.

83. Adams KL, Palmer JD. Evolution of mitochondrial gene content: gene loss and transfer to the nucleus. Mol Phylogenet Evol. 2003;29(3):380-95.

84. Rodriguez-Ezpeleta N, Brinkmann H, Burey SC, Roure B, Burger G, Loffelhardt W, Bohnert HJ, Philippe H, Lang BF. Monophyly of primary photosynthetic eukaryotes: Green plants, red algae, and glaucophytes. Curr Biol. 2005;15(14) 1325-30.

85. Lohr M, Schwender J, Polle JEW. Isoprenoid biosynthesis in eukaryotic phototrophs: a spotlight on algae. Plant Sci. 2012;185:9-22.

86. Koren S, Walenz BP, Berlin K, Miller JR, Bergman NH, Phillippy AM. Canu: scalable and accurate long-read assembly via adaptive k-mer weighting and repeat separation. Genome Res. 2017;27(5):722-36.

87. Chin C-S, Alexander DH, Marks P, Klammer AA, Drake J, Heiner C, Clum A, Copeland A, Huddleston J, Eichler EE, et al. Nonhybrid, finished microbial genome assemblies from long-read SMRT sequencing data. Nat Methods. 2013;10(6):563.

88. Walker BJ, Abeel T, Shea T, Priest M, Abouelliel A, Sakthikumar S, Cuomo CA, Zeng Q, Wortman J, Young SK, et al. Pilon: An Integrated Tool for Comprehensive Microbial Variant Detection and Genome Assembly Improvement. PLoS One. 2014;9(11):e112963.

89. Simao FA, Waterhouse RM, loannidis P, Kriventseva EV, Zdobnov EM. BUSCO: assessing genome assembly and annotation completeness with single-copy orthologs. Bioinformatics. 2015;31(19):3210-2.

90. Thiel T, Michalek W, Varshney RK, Graner A. Exploiting EST databases for the development and characterization of gene-derived SSR-markers in barley (Hordeum vulgare L.). Theor Appl Genet. 2003;106(3):411-22.

91. Bedell JA, Korf I, Gish W. MaskerAid: a performance enhancement to RepeatMasker. Bioinformatics. 2000;16(11):1040-1.

92. Stanke M, Waack S. Gene prediction with a hidden Markov model and a new intron submodel. Bioinformatics. 2003;19:|l215-25.

93. Birney E, Durbin R. Using GeneWise in the Drosophila annotation experiment. Genome Res. 2000;10(4):547-8.

94. Haas BJ, Salzberg SL, Zhu W, Pertea M, Allen JE, Orvis J, White O, Buell CR, Wortman JR. Automated eukaryotic gene structure annotation using EVidenceModeler and the program to assemble spliced alignments. Genome Biol. 2008;9(1):R7.

95. Yagi M, Kosugi S, Hirakawa H, Ohmiya A, Tanase K, Harada T, Kishimoto K, Nakayama M, Ichimura K, Onozaki T, et al. Sequence analysis of the genome of carnation (Dianthus caryophyllus L.). DNA Res. 2014;21(3):231-41.

96. Zdobnov EM, Apweiler R. InterProScan - an integration platform for the signature-recognition methods in InterPro. Bioinformatics. 2001;17(9):847-8.

97. Griffiths-Jones S, Moxon S, Marshall M, Khanna A, Eddy SR, Bateman A. Rfam: annotating non-coding RNAs in complete genomes. Nucleic Acids Res. 2005;33:D121-4

98. Lowe TM, Eddy SR. tRNAscan-SE: a program for improved detection of transfer RNA genes in genomic sequence. Nucleic Acids Res. 1997;25(5): 955-64.

99. Lagesen $\mathrm{K}$, Hallin P, Rodland EA, Staerfeldt H-H, Rognes T, Ussery DW. RNAmmer: consistent and rapid annotation of ribosomal RNA genes. Nucleic Acids Res. 2007;35(9):3100-8.

100. Piganeau G, Eyre-Walker A, Grimsley N, Moreau H. How and why DNA barcodes underestimate the diversity of microbial eukaryotes. PLoS One. 2011;6(2):6

101. Tamura K, Nei M. Estimation of the number of nucleotide substitutions in the control region of mitochondrial DNA in humans and chimpanzees. Mol Biol Evol. 1993;10(3):512-26.

102. Kumar S, Stecher G, Li M, Knyaz C, Tamura K. MEGA X: molecular evolutionary genetics analysis across computing platforms. Mol Biol Evol. 2018;35(6):1547-9.

\section{Publisher's Note}

Springer Nature remains neutral with regard to jurisdictional claims in published maps and institutional affiliations. 